\title{
An I nduced Hesitant Linguistic Aggregation Operator and Its Application for Creating Fuzzy Ontology
}

\author{
Mingming Kong ${ }^{1}$, Fangling Ren ${ }^{2}$, Doo-Soon Park ${ }^{3}$, Fei Hao ${ }^{4}$ and Zheng Pei ${ }^{1}$ \\ ${ }^{1}$ Center for Radio Administration \& Technology Development, Xihua University \\ Chengdu, China \\ [e-mail: kongming000@126.com, pqyz@263.net] \\ ${ }^{2}$ College of Mathematics and Computer Science, Yan'an University \\ Yan’an, China \\ [e-mail: renfangling203@163.com] \\ ${ }^{3}$ Department of Computer Software Engineering, Soonchunhyang University \\ Asan, South Korea \\ [e-mail: parkds@sch.ac.kr] \\ ${ }^{4}$ School of Computer Science, Shaanxi Normal University \\ Xi'an, China \\ [e-mail: feehao@gmail.com] \\ *Corresponding author: Fei Hao
}

Received March 5, 2018; revised April 17, 2018; accepted May 18, 2018;

published October 31, 2018

\begin{abstract}
An induced hesitant linguistic aggregation operator is investigated in the paper, in which, hesitant fuzzy linguistic evaluation values are associated with probabilistic information. To deal with these hesitant fuzzy linguistic information, an induced hesitant fuzzy linguistic probabilistic ordered weighted averaging (IHFLPOWA) operator is proposed, monotonicity, boundary and idempotency of IHFLPOWA are proved. Then andness, orness and the entropy of dispersion of IHFLPOWA are analyzed, which are used to characterize the weighting vector of the operator, these properties show that IHFLPOWA is extensions of the induced linguistic ordered weighted averaging operator and linguistic probabilistic aggregation operator. In this paper, IHFLPOWA is utilized to gather linguistic information and create fuzzy ontologies, and a movie fuzzy ontology as an illustrative case study is used to show the elaboration of the proposed method and comparison with the existing linguistic aggregation operators, it seems that the IHFLPOWA operator is an useful and alternative operator for dealing with hesitant fuzzy linguistic information with probabilistic information.
\end{abstract}

Keywords: Hesitant fuzzy linguistic terms set, 2-tuple linguistic model, linguistic multi-criteria group decision making, fuzzy ontology, linguistic probabilistic aggregation operator. 


\section{Introduction}

Decision making is a cognitive process based on different mental and reasoning processes that lead to the choice of a suitable alternative from a set of possible alternatives in a decision situation [1-3]. Due to the inherent complexity and uncertainty of the decision situation or the existence of multiple and conflicting objectives, human beings often use fuzzy linguistic terms to express complex or uncertain information in decision making process, i.e., assessments of possible alternatives in a decision situation are expresses by fuzzy evaluation linguistic terms, such as comfortable degree of vehicles are often expressed by consumers using linguistic terms “poor, fair, good, perfect”. Up to now, linguistic decision making has been widely used in many applications, such as in [4], linguistic decision making has been utilized to extract users' information and create fuzzy ontologies for storing and sharing people knowledge automatically.

Theoretically, the core of linguistic decision making is fuzzy linguistic information processing method, the remarkable works of fuzzy linguistic information processing was initially proposed by Zadeh in [5], which are rooted on linguistic variable and fuzzy set [6], a linguistic variable is a variable whose values are not numbers, but words or sentences in a natural or artificial language. Linguistic variables provide us a flexible and reliable form to represent qualitative information in decision makings, however, the approach has some limitations due to using membership functions, such as a priori linguistic terms set, limitation of the number of linguistic terms, computational complexity, a lack of accuracy, and loss information in the approximation processes [7]. To overcome these weaknesses, the 2-tuple linguistic model has been proposed in [7], which provides a continuous fuzzy representation for linguistic terms by the translation of the linguistic term obtained from the symbolic computation to the closest linguistic term in the initial linguistic terms set. Up to now, the 2-tuple linguistic model has become a useful and fundamental tool for expressing and handling fuzzy linguistic information, and many new 2-tuple linguistic-inspired models have been developed and used to handle many different real-world decision making [1], such as, $\mathrm{Xu}$ [2] introduced the extended linguistic variable based on the concept of virtual linguistic values to improve the operational laws of symbolic operations. Wang and Hao [8] proposed the linguistic proportional 2-tuple model to represent linguistic information that is a generalization and extension of the 2-tuple linguistic model, Guo et al.[9] extended the linguistic proportional 2-tuple model by using a third parameter to deal with incomplete linguistic preferences. Dong et al. [10] presented the concept of numerical scale with the aim of completing the 2-tuple linguistic model and proportional 2-tuple models and making the elicitation of information more consistent in different decision situations. Li [11] proposed an extended 2-tuple linguistic model that fuses the use of virtual linguistic values and 2-tuple linguistic values. Wei [12] investigated the 2-tuple linguistic multiple attribute group decision making problems in which the information about attribute weights is partially known. Yang [13] developed the counted linguistic variable for representing and aggregating linguistic information with the aim of providing better results and being easier to understand. Cables et al. [14] proposed a decision making method in which the decision makers provided their assessment information to represent their qualitative preferences under 2-tuple linguistic environment. Moreover, many 2-tuple linguistic aggregation operators have been proposed in literatures [15-25] to make the aggregation of linguistic information much more flexible, we refer [1, 7] for more details about 2-tuple linguistic model and decision makings based on 2-tuple linguistic model. Motivated by hesitant fuzzy sets [26] and 2-tuple linguistic model, the concept of hesitant fuzzy linguistic term sets (HFLTSs) have been proposed in [27] to deal with hesitant fuzzy 
linguistic information in linguistic decision makings. HFLTSs have attracted many scholars' attention since its appearance and some research results have been presented [28-30], for example, Wei, et al. [31] defined two aggregation operators for HFLTSs: a hesitant fuzzy LWA operator and a hesitant fuzzy LOWA operator after defining operations on HFLTSs and possibility degree formulas for comparing HFLTSs. Wang, et al. [32] proposed a new approach to solve multi-criteria group decision-making problems in which the criteria are in different priority levels and the criteria values take the form of interval-valued hesitant fuzzy linguistic numbers. Chen, et al. [33] presented a new method for multi-criteria group decision making based on hesitant fuzzy linguistic term sets using the pessimistic attitude and the optimistic attitude of the decision maker. Wang, et al. [34] proposed an outranking approach for multi-criteria group decision-making with hesitant fuzzy linguistic term sets. Liao, et al. [35] developed different types of distance and similarity measures for HFLTS, based on which an approach for multi-criteria decision making problem is given. Liu, et al. [36] presented a new representation of HFLTS by means of a fuzzy envelope and applied it to multi-criteria group decision making. Zhang [37] presented hesitant fuzzy power aggregation operators for multi-criteria group decision making. Zhang, et al. [38] proposed an approach to solve the problem of ranking alternatives expressed with HFLTSs, four uncertain hesitant fuzzy linguistic aggregation operators and an approach to hesitant fuzzy linguistic multiple attribute decision making. Lee, et al. [39] devised a new fuzzy decision making method and a new fuzzy group decision making method based on the proposed likelihood-based comparison relations of HFLTSs and the four proposed aggregation operators of HFLTSs.

Probabilistic information have been also widely considered in decision making, especially, aggregation operators with probabilistic information have been widely studied, such as $\mathrm{Wu}$ [40] provided a possibility distribution based approach to carry out the aggregation process of HFLTSs. Zeng, et al. [41] used distance measures in a unified framework between the probability and the ordered weighted averaging (OWA) operator to present the uncertain probabilistic OWA distance operator and applied it to a group decision making problem. Merig'o, et al. [42] presented the probabilistic ordered weighted averaging distance (POWAD) operator that uses a unified model between probabilities and the OWA operator considering the degree of importance that each concept has. Merig'o, et al. [43] presented the induced linguistic probabilistic ordered weighted average (ILPOWA) operator using probabilities and the OWA operator in the same formulation and developed a new approach for linguistic group decision making based on the ILPOWA operator. Merig'o, et al. [44] introduced the uncertain generalized probabilistic weighted averaging (UGPWA) operator unifying the probability and the weighted average in the same formulation and analyzed its applicability in a group decision making problem. Merig'o [45] introduced the probabilistic OWA (POWA) operator considering the degree of importance that the probability and the OWA operator have in the aggregation and analyzed its applicability in group decision making.

In many real world practices, when a decision maker is asked to provide his/ her preference on an alternative with respect to a criterion, there exists the following case: on the one hand, the decision maker may be hesitant between several linguistic terms; on the other hand, based on his/her knowledge, experience, cultural foundation, and educational background, the decision maker may prefer to use ones of the linguistic terms than others to evaluate the alternative, for example, suppose a set of nine linguistic terms be 


$$
S=\left\{\begin{array}{l}
s_{0}=\text { extremely low }(E L), s_{1}=\text { very low }(V L), s_{2}=\text { low }(L), \\
s_{3}=\text { slightly low }(S L), s_{4}=\text { medium }(M), s_{5}=\text { slightlyhigh }(S H), \\
s_{6}=\text { high }(H), s_{7}=\text { very high }(V H), s_{8}=\text { extremely high }(E H)
\end{array}\right\} .
$$

On the one hand, the decision maker might be hesitant between the linguistic terms " $H$ " and " $V H$ " when he/ she evaluates an alternative with respect to a criterion; On the other hand, due to his/ her knowledge, experience, cultural foundation, and educational background, the decision maker may prefer to use the linguistic term " $V H$ " than " $H$ " to evaluate the alternative. In such case, only the HFLTS $\left\{s_{6}, s_{7}\right\}$ cannot sufficiently reflect the decision maker's opinion, combing the HFLTS and probabilistic information maybe a good idea, i.e., $\left\{\left(s_{6}, 0.3\right),\left(s_{7}, 0.7\right)\right\}$, where 0.7 and 0.3 indicate the possibility of " $V H$ " and " $H$ " used by the decision maker, respectively. In real world practices, $\left\{\left(s_{6}, 0.3\right),\left(s_{7}, 0.7\right)\right\}$ means that the decision maker is hesitant between $s_{6}$ and $s_{7}$ as well as the decision maker prefers to use $s_{7}$ (with possibility 0.7 ) than $s_{6}$ (with possibility 0.3). Accordingly, the major contributions of the paper are summarized as follows:

(1) Hesitant fuzzy linguistic term sets with probabilistic information is formalized in this paper, which can be used to express evaluation linguistic information with hesitancy and preference;

(2) An induced hesitant fuzzy linguistic probabilistic ordered weighted averaging (IHFLPOWA) operator is proposed to aggregate hesitant fuzzy linguistic term sets with probabilistic information and properties of the IHFLPOWA operator are analyzed, which show that the IHFLPOWA operator is an extension of several existed linguistic aggregation operators;

(3) The IHFLPOWA operator is utilized to create a movie fuzzy ontology, in which evaluations of alternatives (movies) are hesitant fuzzy linguistic term sets with probabilistic information provided by Internet users.

The rest of this paper is organized as follows: In Section 2, we briefly review 2-tuple linguistic model, hesitant fuzzy linguistic term sets, several basic linguistic aggregation operators and fuzzy ontology. In Section 3, we propose the IHFLPOWA operator and analyze some different types of the IHFLPOWA operator by considering particular cases of the weighting vector. In Section 4, inspired by interesting works on fuzzy ontology [4], a movie's fuzzy ontology is provided to show feasibility and efficiency of the IHFLPOWA operator in extract users' hesitant fuzzy linguistic and probabilistic information and create knowledge databases for storing and sharing people knowledge automatically. Section 5 concludes this paper.

\section{Preliminaries}

Formally, 2-tuple linguistic model [5] is described as follows: Let $S=\left\{s_{0}, s_{1}, \cdots, s_{g}\right\}$ be a set of linguistic terms and $\beta \in[0, g]$ be a value supporting the result of a symbolic aggregation operation. Then a 2-tuple linguistic value that expresses the equivalent information to $\beta$ is obtained with the function $\Delta:[0, g] \rightarrow \bar{S}$ such that $\Delta(\beta)=\left(s_{i}, \alpha\right)$ with $i=\operatorname{round}(\beta)$ and $\alpha=\beta-i \in[-0.5,0.5)$, where $s_{i}$ has the closest index label to $\beta$ and $\alpha$ is the value of the symbolic translation, round(.) is the usual round operation. The ordering of linguistic 
information is processed by the linear ordered structure of linguistic values, and their natural number indexes are used to explain the ordering, i.e., for any 2-tuple linguistic values $\left(s_{i}, \alpha_{i}\right) \quad$ and $\left(s_{j}, \alpha_{j}\right) \quad, \quad\left(s_{i}, \alpha_{i}\right) \leq\left(s_{j}, \alpha_{j}\right) \quad$ if $\quad$ and only if $\Delta^{-1}\left(s_{i}, \alpha_{i}\right)=i+\alpha_{i} \leq \Delta^{-1}\left(s_{j}, \alpha_{j}\right)=j+\alpha_{j} \quad$ all linguistic 2-tuples are denoted by $\bar{S}=\left\{\left(s_{i}, \alpha_{i}\right) \mid s_{i} \in S, \alpha \in[-0.5,0.5)\right\}$.

Hesitant fuzzy set on $X$ is a function $h$ that returns a subset of values in [0,1], where $X$ is a reference set [26]. A hesitant fuzzy set $h_{M}$ associated to $M$ is defined as $h_{M}(x)=\bigcup_{\mu_{i} \in M}$ $\left\{\mu_{i}(x)\right\}$, where $M=\left\{\mu_{1}, \mu_{2}, \cdots \mu_{n}\right\}$ be a set of membership functions. Given a hesitant fuzzy set $h$, its lower bound $h^{-}(x)$, upper bound $h^{+}(x)$ and complement $h^{c}$ are defined as $h^{-}(x)=\min h(x), h^{+}(x)=\max h(x)$ and $h^{c}=\bigcup_{\gamma \in h}\{1-\gamma\}$, respectively.

\subsection{Hesitant Fuzzy Linguistic Term Sets}

HFLTSs have been proposed to deal with the situations where decision makers have hesitancy in providing their linguistic preferences over objects [27]. Formally, an HFLTS, $H_{S}$, is an ordered finite subset of the consecutive linguistic terms of $S=\left\{s_{0}, s_{1}, \cdots, s_{g}\right\}$, such as $H_{S}=\left\{s_{3}, s_{4}, s_{5}\right\}$. Some of its basic operations of hesitant fuzzy linguistic information are briefly viewed as follows.

- Lower bound: $H_{S^{-}}=\min \left(s_{i}\right)=s_{j}, s_{i} \in H_{S}$ and $s_{i} \geq s_{j} \forall i$;

-Upper bound: $H_{S^{+}}=\max \left(s_{i}\right)=s_{j}, s_{i} \in H_{S}$ and $s_{i} \leq s_{j} \forall i$;

-Complement: $H_{S}^{c}=S-H_{S}=\left\{s_{i} \mid s_{i} \in S\right.$ and $\left.s_{i} \not \subset H_{S}\right\}$;

-Union: $H_{S}^{1} \bigcup H_{S}^{2}=\left\{s_{i} \mid s_{i} \in H_{S}^{1}\right.$ or $\left.s_{i} \in H_{S}^{2}\right\}$,

-Intersection: $H_{S}^{1} \bigcap H_{S}^{2}=\left\{s_{i} \mid s_{i} \in H_{S}^{1}\right.$ and $\left.s_{i} \in H_{S}^{2}\right\}$;

-Envelope: env $\left(H_{S}\right)=\left[H_{S^{-}}, H_{S^{+}}\right]$.

The envelope of a HFLTS is a linguistic interval whose limits are obtained by means of upper bound (max) and lower bound (min). Based on the envelopes of HFLTSs, the follows can be defined [27]

$$
\begin{aligned}
& H_{S}^{1}(\theta)>H_{S}^{2}(\theta) \text { if and only if env }\left(H_{S}^{1}(\theta)\right)>\operatorname{env}\left(H_{S}^{2}(\theta)\right), \\
& H_{S}^{1}(\theta)=H_{S}^{2}(\theta) \text { if and only if } \operatorname{env}\left(H_{S}^{1}(\theta)\right)=\operatorname{env}\left(H_{S}^{2}(\theta)\right) .
\end{aligned}
$$

Accordingly, the comparison among HFLTSs can be converted into the comparison among their envelopes.

\subsection{Linguistic or HFLTSs Aggregation Operators}

Here, we briefly review several important linguistic or HFLTSs aggregation operators, which are widely used in linguistic decision making problems.

- The LWA operator [46]: A LWA operator of dimension $n$ is a mapping, LWA: $S^{n} \rightarrow \bar{S}$, 
that has an associated vector $w=\left(w_{1}, w_{2}, \cdots, w_{n}\right)^{T}$ such that $w_{j} \in[0,1]$ and $\sum_{j=1}^{n} w_{j}=1$. Furthermore,

$$
\operatorname{LWA}\left(s_{a_{1}}, s_{a_{2}}, \cdots, s_{\alpha_{n}}\right)=\Delta\left(\sum_{i=1}^{n} w_{i} \Delta^{-1}\left(s_{a_{i}}, 0\right)\right),
$$

where $s_{\alpha_{i}}(i=1,2, \cdots, n)$ are the aggregated values.

- The LOWA operator [47]: A LOWA operator of dimension $n$ is a mapping LOWA: $S^{n} \rightarrow \bar{S}$, which has an associated weighting vector $W$ such that $w_{j} \in[0,1]$ and $\sum_{j=1}^{n} w_{j}=1$.Furthermore,

$$
\operatorname{LOWA}\left(s_{\alpha_{1}}, s_{\alpha_{2}}, \cdots, s_{\alpha_{n}}\right)=\Delta\left(\sum_{j=1}^{n} w_{j} \Delta^{-1}\left(s_{\beta_{j}}, 0\right)\right),
$$

where $s_{\beta_{j}}$ is the $j$ th largest element in $\left\{s_{\alpha_{1}}, s_{\alpha_{2}}, \cdots, s_{\alpha_{n}}\right\}$.

- The IULOWA operator [48]: An induced uncertain linguistic OWA (IULOWA) operator is a mapping as follows

$$
\operatorname{IULOWA}\left(\left\langle u_{1}, \tilde{s}_{1}\right\rangle, \cdots,\left\langle u_{n}, \tilde{s}_{n}\right\rangle\right)=w_{1} \tilde{s}_{\beta_{1}} \oplus \cdots \oplus w_{n} \tilde{s}_{\beta_{n}},
$$

where $w=\left(w_{1}, w_{2}, \cdots, w_{n}\right)$ is a weighting vector, such that $w_{j} \in[0,1], \sum_{j=1}^{n} w_{j}=1, \widetilde{s}_{\beta_{j}}$ is the value $\widetilde{s}_{i}$ of the pair $\left\langle\boldsymbol{u}_{i}, \widetilde{s}_{i}\right\rangle$ having the jth largest $u_{i}$, and $u_{i}$ in $\left\langle\boldsymbol{u}_{i}, \widetilde{\boldsymbol{s}}_{i}\right\rangle$ is referred as the order inducing variable and $\tilde{s}_{i}$ as the uncertain linguistic argument variable, i.e., $\tilde{s}_{i}=\left[s_{\alpha_{i}}, s_{\beta_{i}}\right]\left(\alpha_{i}<\beta_{i}, s_{\alpha_{i}}, s_{\beta_{i}} \in S\right)$.

- The ILPOWA operator [43]: An ILPOWA operator of dimension $n$ is a mapping ILPOWA: $S^{n} \times S^{n} \rightarrow S$ with an associated weighting vector $W$ of dimension $n$ and probability $P$ such that $\sum_{j=1}^{n} w_{j}=1$ and $w_{j} \in[0,1], \sum_{i=1}^{n} p_{i}=1, p_{i} \in[0,1]$, respectively, i.e.,

$$
\operatorname{ILPOWA}\left(\left\langle u_{1}, s_{a_{1}}\right\rangle, \cdots,\left\langle u_{n}, s_{a_{n}}\right\rangle\right)=\Delta\left(\sum_{j=1}^{n} \breve{v}_{j} \Delta^{-1}\left(s_{\beta_{j}}, 0\right)\right) \text {, }
$$

where $s_{\beta_{j}}$ is the $j$ th largest linguistic value $s_{\alpha_{i}}$ induced by $u_{i}, \breve{v}_{j}=\beta w_{j}+(1-\beta) p_{j}$ with $\beta \in[0,1]$ and $p_{j}$ is the probability of $s_{\alpha_{i}}$ induced by $u_{i}$. Due to $\breve{v}_{j}=\beta w_{j}+(1-\beta) p_{j}$, the ILPOWA operator can also be rewritten as follows

$$
\operatorname{ILPOWA}\left(\left\langle u_{1}, s_{a_{1}}\right\rangle, \cdots,\left\langle u_{n}, s_{a_{n}}\right\rangle\right)=\Delta\left(\beta \sum_{j=1}^{n} w_{j} \Delta^{-1}\left(s_{\beta_{j}}, 0\right)+(1-\beta) \sum_{i=1}^{n} p_{i} \Delta^{-1}\left(s_{a_{i}}, 0\right)\right) \text {, }
$$

Based on the above mentioned linguistic aggregation operators, we notice that the LOWA operator defined by (2) is an extension of the LWA operator defined by (1) if $s_{\beta_{j}}$ is actually equal to $s_{\alpha_{j}}$, the IULOWA operator defined by (3) is an extension of the LOWA operator 
defined by (2) if $s_{\alpha_{i}}=s_{\beta_{i}}$ for any $\tilde{s}_{i}=\left[s_{\alpha_{i}}, s_{\beta_{i}}\right]$ and the order induced by $u_{i}$ is actually equal to the order induced by $\widetilde{s}_{i}$. Formally, if $\beta=1$, then the ILPOWA operator defined by (4) or (5) reduces to the induced linguistic OWA operator. If $\beta=0$, then the ILPOWA operator defined by (4) or (5) reduces to the linguistic probabilistic aggregation operator.

Several aggregation operators of HFLTSs have been proposed as follows:

- The HLWA operator [31]: Let $S=\left\{s_{0}, \cdots, s_{g}\right\}$ be a linguistic term set, $H_{S}^{1}, \cdots, H_{S}^{n}$ be $n$

HFLTSs on $S$. Let $w=\left(w_{1}, w_{2}, \cdots, w_{n}\right)^{T}$ be a weighting vector of $H_{S}^{j}(j=1, \cdots, n)$ with $w_{j} \geq 0(j=1, \cdots, n)$ and $\sum_{j=1}^{n} w_{j}=1$.Then, the hesitant fuzzy linguistic weighted aggregation (HLWA) operator is defined as

$$
\begin{aligned}
& \operatorname{HLWA}\left(H_{s}^{1}, \cdots, H_{S}^{n}\right)=C^{n}\left\{w_{k}, H_{s}^{k}, k=1,2, \cdots, n\right\} \\
& =w_{1} \odot H_{s}^{1} \oplus\left(1-w_{1}\right) \odot C^{n-1}\left\{\frac{w_{h}}{\sum_{k=2}^{n} w_{k}}, H_{s}^{h}, h=2, \cdots, n\right\} .
\end{aligned}
$$

- The HLOWA operator [31]: Let $S, H_{S}^{i}(i=1, \cdots, n)$ be as before. The hesitant fuzzy LOWA (HLOWA) operator is defined as

$$
\begin{gathered}
\operatorname{HLOWA}\left(H_{S}^{1}, \cdots, H_{s}^{n}\right)=C^{n}\left\{w_{k}, H_{s}^{\sigma_{k}}, k=1,2, \cdots, n\right\} \\
=w_{1} \odot H_{S}^{\sigma_{k}} \oplus\left(1-w_{1}\right) \odot C^{n-1}\left\{\frac{w_{h}}{\sum_{k=2}^{n} w_{k}}, H_{S}^{\sigma_{h}}, h=2, \cdots, n\right\},
\end{gathered}
$$

where $w=\left(w_{1}, w_{2}, \cdots, w_{n}\right)^{T}$ is an associated weighting vector of the operator with $w_{j} \in[0,1]$ and $\sum_{j=1}^{n} w_{j}=1 ;\left(H_{S}^{\sigma_{1}}, \cdots, H_{S}^{\sigma_{n}}\right)$ is a permutation of $H_{S}^{1}, \cdots, H_{S}^{n}$ such that $H_{S}^{\sigma_{i}}>H_{S}^{\sigma_{j}}$ or $H_{S}^{\sigma_{i}} \triangleright H_{S}^{\sigma_{j}}$ for all $i<j$.

- The UHFLOWA operator [38]: An uncertain hesitant fuzzy linguistic ordered weighted averaging operator UHFLOWA: $\tilde{\mathrm{S}}^{\mathrm{n}} \rightarrow \tilde{\mathrm{S}}$ is defined as

$$
\operatorname{UHFLOWA}\left(H_{S}^{1}, H_{S}^{2}, \cdots, H_{S}^{n}\right)=w_{1} \tilde{H}_{S}^{1} \oplus \cdots \oplus w_{n} \tilde{H}_{S}^{n},
$$

where $\tilde{S}$ is the set of all HFLTSs, $\tilde{H}_{S}^{i}(i=1,2, \cdots, n)$ is the $i$ th largest of $\tilde{H}_{S}^{j}(j=1,2$, $\cdots, n)$ and $w=\left(w_{1}, w_{2}, \cdots, w_{n}\right)^{T}$ is weights.

- The UHFLWA operator [38]: An uncertain hesitant fuzzy linguistic weighted averaging operator UHFLWA: $\tilde{S}^{n} \rightarrow S^{n}$, is defined as

$$
\operatorname{UHFLWA}\left(H_{S}^{1}, H_{S}^{2}, \cdots, H_{S}^{n}\right)=\omega_{1} H_{S}^{1} \oplus \cdots \oplus \omega_{n} H_{S}^{n},
$$

where $\omega=\left(\omega_{1}, \omega_{2}, \cdots, \omega_{n}\right)^{T}$ is the weighting vector of hesitant fuzzy linguistic variables $\tilde{H}_{S}^{i}(i=1,2, \cdots, n) \sum_{i=1}^{n} \omega_{i}=1$ and $\omega_{i} \geq 0$.

- The UHFLHA operator [38]: An uncertain hesitant fuzzy linguistic hybrid aggregation 
operator UHFLHA: $\tilde{S}^{n} \rightarrow \tilde{S}$ is defined as

$$
\text { UHFLH } A_{\omega, w}=w_{1} \bar{H}_{S}^{1} \oplus \cdots \oplus w_{n} \bar{H}_{S}^{n},
$$

where $\bar{H}_{S}^{i}$ is the $i$ th largest of $\dot{H}_{S}^{j}\left(\dot{H}_{S}^{j}=n \omega_{j} H_{S}^{j}, j=1, \cdots, n\right), w=\left[w_{1}, w_{2}, \cdots, w_{n}\right]^{T}$ and $\omega=\left[\omega_{1}, \omega_{2}, \cdots, \omega_{n}\right]^{T}$ satisfy $0 \leq w_{i}, \omega_{i} \leq 1(i=1, \cdots, n), \sum_{i=1}^{n} w_{i}=1$ and $\sum_{i=1}^{n} \omega_{i}=1$.

It is obvious that if $w_{i}=\frac{1}{n}(i=1, \cdots, n)$, then the UHFLHA operator defined by (10) is reduced to the UHFLWA operator defined by (9). If $\omega_{i}=\frac{1}{n}(i=1, \cdots, n)$, then the UHFLOWA operator defined by (8) is reduced to the HLOWA operator defined by (7) .

\subsection{Fuzzy ontology}

On the one hand, the Internet has become a place where users can connect and share large amounts of information, this means that Internet users have become providing and consuming information entities and information is more accessible and available than ever. On the other hand, in most cases, the Internet information is little used by users because it is badly structured. It seems that ontologies [53] are tools that provide a way of sorting, classifying and describing large amounts of Internet information, and knowledge databases created using ontologies are easy to manage and allow users to search for information and extract conclusions [4]. Theoretically, crisp ontologies allow each element to be described or not by each concept in the ontology, however in the Internet environments, users often provide imprecision conceptual information, this means that each element is described by each concept using a particular degree in the interval $[0,1]$ or linguistic terms such as Low, Medium or High, fuzzy ontologies as tools are used to solve the such problem. Formally, a fuzzy ontology [54] is a quintuple $O=\{I, C, R, F, A\}$, where $I$ is a set of individuals, $C$ is a set of concepts, $R$ is the set of relations, $F$ is a set of fuzzy relations which allow individuals to be related to concepts or other individuals to a certain degree and $A$ is the set of axioms. In crisp ontologies, each individual is related or not to each concept or individual, i.e., $\{0,1\}$. In fuzzy ontologies, individuals can establish relations in a fuzzy way, such as using a membership function, the interval $[0,1]$ or linguistic terms $[5,6]$.

The method to create automatic knowledge ontology using information from Internet users includes the following four steps [4]:

1. Individuals and concepts definition: Each designed fuzzy ontology is related to a certain topic. Therefore, first, it is necessary to identify the individuals and concepts that are related with the topic that is being dealt with and the relations among the different elements that the fuzzy ontology is comprised of. In this paper, it is considered that every individual is related to every concept. Also, it is assumed that individuals are not related.

2. Ranking process: Group decision making processes are used in order for Internet users to be able to define the values of the relations between each individual and concept.

3. Fuzzy ontology creation process: Once the relation values between each individual and concept are defined, the fuzzy ontology can be created by gathering the information. As a result, the knowledge that has been provided by the users is stored in an organized way. Also, other Internet users can access and benefit from it. Intuitively, the fuzzy ontology creation process follows ranking linguistic term set association and fuzzy ontology structure 
construction, ranking linguistic term set association means that a $S=\left\{s_{0}, s_{1}, \cdots, s_{g}\right\}$ containing the same number of labels as individuals in the fuzzy ontology is defined. The label indicating the highest value is assigned to the first individual in the ranking, the second highest value to the second position in the ranking and so on. After applying the ranking linguistic term set association to all the concepts in the fuzzy ontology, the information is gathered and the fuzzy ontology is constructed.

4. Fuzzy ontology consulting process: The step is followed so that Internet users can retrieve information.

In this paper, we select a movie fuzzy ontology as an illustrative case study (Section 4) to show creating fuzzy ontology based on linguistic aggregation operator, in which, each individual related to each concept is described by hesitant fuzzy linguistic term sets on $S=\left\{s_{0}=E L, s_{1}=V L, s_{2}=L, s_{3}=S L, s_{4}=M, s_{5}=S H, s_{6}=H, s_{7}=V H, s_{8}=E H\right\}$ with probabilistic information, and the induced hesitant fuzzy linguistic probabilistic OWA operator is used to gather the hesitant fuzzy linguistic information and create the movie fuzzy ontology.

\section{The Induced Hesitant Fuzzy Linguistic Probabilistic OWA Operator}

In this section, we firstly consider hesitant fuzzy linguistic term sets with probabilistic information provided by decision makers, then we propose an induced hesitant fuzzy linguistic probabilistic OWA (IHFLPOWA) operator to deal with hesitant fuzzy linguistic term sets with probabilistic information and analyze several properties of the IHFLPOWA operator.

\subsection{The IHFLPOWA Operator}

Let $S=\left\{s_{0}, s_{1}, \cdots, s_{g}\right\}$ be an initial linguistic term set. A hesitant fuzzy linguistic term set with probabilistic information can be formalized as $H^{P}=\left\{\left(s_{\alpha_{1}}, p_{1}\right), \cdots,\left(s_{\alpha_{n}}, p_{n}\right)\right\}$, where $\sum_{i=0}^{g} p_{i}=1$ and $p_{i} \in[0,1]$, all $H^{P}$ on $S$ can be denoted as

$$
L_{h p}=\left\{H^{P}=\left\{\left(s_{\alpha_{1}}, p_{1}\right), \cdots,\left(s_{\alpha_{n}}, p_{n}\right)\right\} \mid \forall H^{P}, s_{\alpha_{i}} \in S, \sum_{i=0}^{n} p_{i}=1 p_{i} \in[0,1], 1 \leq n \leq g+1\right\} .
$$

In practices, $H^{P}$ can be explained from the following two aspects: One is that $H^{P}$ expresses hesitancy of decision makers, the other is that each element $s_{\alpha_{i}}$ in $H^{P}$ has a probability $p_{i}$ according to the habits of language use, perceptions for linguistic values and knowledge background of decision makers, or the decision maker prefer to use $s_{\alpha_{i}}$ as evaluation linguistic value than $s_{\alpha_{i^{\prime}}}$ if $p_{i} \geq p_{\mathrm{i}^{\prime}}$. To deal with $H^{P}$ in decision making, we propose the following IHFLPOWA operator.

An IHFLPOWA operator of dimension $n$ is a mapping IHFLPOWA: $\left(L_{h p}\right)^{n} \times\left(L_{h p}\right)^{n} \rightarrow \bar{S}$ that has an associated weighting vector $W$ of dimension $n$ such that $w_{j} \in[0,1]$ and $\sum_{j=1}^{n} w_{j}=1$, i.e.,

$$
\operatorname{IHFLPOWA}\left(\left\langle u_{1}, H_{1}^{P}\right\rangle, \cdots,\left\langle u_{n}, H_{n}^{P}\right\rangle\right)=\Delta\left(\sum_{j=1}^{n} w_{j} \Delta^{-1}\left(H_{j}^{P}\right)\right)=\Delta\left(\sum_{j=1}^{n} w_{j}\left(\sum_{k=1}^{l_{j}} p_{k j} \Delta^{-1}\left(s_{k j}\right)\right)\right),
$$


in which, for any $i \in\{1, \cdots, n\}, u_{i}$ is the order inducing variable of $H_{i}^{p} \in L_{h p}$, i.e. $H_{j}{ }^{P}$ is the hesitant fuzzy linguistic term set $H_{i}{ }^{P}$ with probabilistic information in $\left\{H_{i}^{P} \mid H_{i}^{P}=\left\{\left(s_{1 i}, p_{1 i}\right), \cdots,\left(s_{l_{i}}, p_{l_{i}}\right) \in L_{h p}, i=1, \cdots, n\right\}\right.$ induced by the $j$ th largest $u_{i}$. Example 1 Let a linguistic term set be $S=\left\{s_{0}, \cdots, s_{8}\right\}$. Assume the following hesitant fuzzy linguistic term sets with probability information in the aggregation process:

$H_{1}^{P}=\left\{\left(s_{2}, 0.5\right),\left(s_{3}, 0.3\right),\left(s_{4}, 0.2\right)\right\} \quad, \quad H_{2}^{P}=\left\{\left(s_{6}, 0.6\right),\left(s_{7}, 0.4\right)\right\}, \quad H_{3}^{P}=\left\{\left(s_{5}, 1\right)\right\} \quad$, $H_{4}^{P}=\left\{\left(s_{4}, 0.5\right),\left(s_{5}, 0.2\right),\left(s_{6}, 0.2\right),\left(s_{7}, 0.1\right)\right\}$. Referring to [43], we assume the weighting vector $w=\left(w_{1}, w_{2}, w_{3}, w_{4}\right)=(0.2,0.2,0.3,0.3)$ and the order inducing variables $U=\left(u_{1}, u_{2}, u_{3}, u_{4}\right)$ $=(8,4,9,6)$. According to the probabilistic weighting vector $P_{i}(i=1,2,3,4)$ of each hesitant fuzzy linguistic term set, we know the decision maker holds a pessimistic attitude towards this aggregation process. Using the IHFLPOWA operator defined by (11) to aggregate the existed information, we have

1. Reorder these $H_{i}^{P}$ according to the order inducing variable $u_{i}(i=1,2,3,4)$, we have $u_{3}>u_{1}>u_{4}>u_{2}$ and thus the order of $H_{i}^{P}$ is listed as $H_{3}^{P}>H_{1}^{P}>H_{4}^{P}>H_{2}^{P}$.

2. Aggregate the linguistic values $s_{k i}\left(k=1, \cdots, l_{i}\right)$ in each hesitant fuzzy linguistic term set $H_{i}^{P}(i \in 1, \cdots, n)$ with the $j$ th largest $u_{i}$ and obtain the result $\Delta^{-1}\left(H_{j}{ }^{P}\right)(j=1,2,3,4)$ as follows $\Delta^{-1}\left(H_{1}^{P}\right)=1 \times \Delta^{-1}\left(S_{5}\right)=1 \times 5=1$,

$\Delta^{-1}\left(H_{2}^{P}\right)=0.5 \times \Delta^{-1}\left(s_{2}\right)+0.3 \times \Delta^{-1}\left(s_{3}\right)+0.2 \times \Delta^{-1}\left(s_{4}\right)=2.7$, $\Delta^{-1}\left(H_{3}^{p}\right)=0.5 \times \Delta^{-1}\left(s_{4}\right)+0.2 \times \Delta^{-1}\left(s_{5}\right)+0.2 \times \Delta^{-1}\left(s_{6}\right)+0.1 \times \Delta^{-1}\left(s_{7}\right)=4.9$ and $\Delta^{-1}\left(H_{4}^{P}\right)=0.6 \times \Delta^{-1}\left(s_{6}\right)+0.4 \times \Delta^{-1}\left(s_{7}\right)=6.4$.

3. IHFLPOWA

$$
=\Delta\left(\sum_{j=1}^{4} w_{j} \Delta^{-1}\left(H_{j}^{P}\right)\right)=\Delta(0.2 \times 5+0.2 \times 2.7+0.3 \times 4.9+0.3 \times 6.4)=\left(s_{5},-0.07\right) .
$$

Note that in the case of ties in the reordering process of the inducing variables [43], we recommend the methodology provided by Yager [49] that replaces these tied arguments by their average.

Theorem 1 The IHFLPOWA operator defined by (11) is monotonic, bounded and idempotent. Proof Based on (11), we have

1) Monotonicity: For any $i$, let $H_{i}^{P}=\left\{\left(s_{1 i}, p_{1 i}\right), \cdots,\left(s_{l_{i}}, p_{l_{i}}\right)\right\}$ and

$$
\begin{aligned}
& H_{i}^{P^{\prime}}=\left\{\left(s_{1 i}^{\prime}, p_{i_{i}}^{\prime}\right), \cdots,\left(s_{l_{i}}^{\prime}, p_{l_{i}}^{\prime}\right)\right\} \text {. If } s_{k i} \leq s_{k i}^{\prime}, p_{k i}=p_{k i}^{\prime}, \forall k, i \text {, then } \sum_{k=1}^{l_{i}} p_{k i} \Delta^{-1}\left(s_{k i}\right) \leq \sum_{k=1}^{l_{i}} p_{k i}^{\prime} \Delta^{-1}\left(s_{k i}^{\prime}\right), \\
& \text { i.e., } \Delta^{-1}\left(H_{j}^{P}\right) \leq \Delta^{-1}\left(H_{j}^{P^{\prime}}\right) \text {.Hence, IHFLPOWA }\left(\left\langle u_{1}, H_{1}^{P}\right\rangle, \cdots,\left\langle u_{n} H_{n}^{P}\right\rangle\right) \\
& =\Delta^{-1}\left(\sum_{j=1}^{n} w_{j} \Delta^{-1}\left(H_{j}^{P}\right)\right) \leq \Delta\left(\sum_{j=1}^{n} w_{j} \Delta^{-1}\left(H_{j}^{P^{\prime}}\right)\right)=\operatorname{IHFLPOWA}\left(\left\langle u_{1}, H_{1}^{P^{\prime}}\right\rangle, \cdots,\left\langle u_{n}, H_{n}^{P^{\prime}}\right\rangle\right) .
\end{aligned}
$$


2) Boundary: According to the concept of union between two HFLTSs, we denote $\operatorname{env}\left(H_{i}^{P}\right)=\left[H_{i^{-}}^{P}, H_{i^{+}}^{P}\right]$ for all $i$. Since $H_{i^{-}}^{P} \leq S_{k i} \leq H_{i^{+}}^{P}$ for all $k, i$, we have $\min \left\{H_{i^{-}}^{P} \mid i=1, \cdots, n\right\} \leq s_{k i} \leq \max \left\{H_{i^{+}}^{P} \mid i=1, \cdots, n\right\}$ for all $k$, i. Denote $s_{\alpha}=\min \left\{H_{i^{-}}^{P} \mid i=1, \cdots, n\right\}$ and $s_{\beta}=\max \left\{H_{i^{+}}^{P} \mid i=1, \cdots, n\right\}$, then $\Delta^{-1}\left(H_{j}^{P}\right)=\sum_{k=1}^{l_{j}} p_{k j} \Delta^{-1}\left(s_{k j}\right) \geq \sum_{k=1}^{l_{j}} p_{k j} \Delta^{-1}\left(s_{\alpha}\right)=\Delta^{-1}\left(s_{\alpha}\right)$, where $\Delta\left(\Delta^{-1}\left(H_{j}^{P}\right)\right)$ is the aggregation result of the linguistic terms in $H_{i}^{P}$ with the $j$ th largest $u_{i}$, then we have

$$
\begin{gathered}
\sum_{j=1}^{n}\left(w_{j}\left(\sum_{k=1}^{l_{j}} p_{k j} \Delta^{-1}\left(s_{k j}\right)\right)\right)=\sum_{j=1}^{n} w_{j} \Delta^{-1}\left(H_{j}^{P}\right) \geq \sum_{j=1}^{n} w_{j} \Delta^{-1}\left(s_{\alpha}\right)=\Delta^{-1}\left(s_{\alpha}\right) . \text { Similarly } \\
\sum_{j=1}^{n}\left(w_{j}\left(\sum_{k=1}^{l_{j}} p_{k j} \Delta^{-1}\left(s_{k j}\right)\right)\right) \leq \Delta^{-1}\left(s_{\beta}\right), \text { i.e., } s_{\alpha} \leq \Delta\left(\sum_{j=1}^{n}\left(w_{j}\left(\sum_{k=1}^{l_{j}} p_{k j} \Delta^{-1}\left(s_{k j}\right)\right)\right)\right) \leq s_{\beta} \text { and } \\
\min \left\{H_{i^{-}}^{P} \mid i=1, \cdots, n\right\} \leq \text { IHFLPOWA } \leq \max \left\{H_{i^{+}}^{P} \mid i=1, \cdots, n\right\} .
\end{gathered}
$$

3) Idempotency: If $\operatorname{env}\left(H_{i}^{P}\right)=e n v\left(H^{P}\right)$ for all $i$ and all of the $H_{i}^{P}$ have the same probability information, i.e., $P_{i}=P, \forall i$, where $P$ is the probabilistic weighting vector of $H^{P}$, then $H_{i}^{P}=H^{P}$ and $\Delta^{-1}\left(H_{j}^{P}\right)=\sum_{k=1}^{l_{j}} p_{k j} \Delta^{-1}\left(s_{k j}\right)=\Delta^{-1}\left(H^{P}\right)$ for all $j$, then

$$
\operatorname{IHFLPOWA}\left(\left\langle u_{1}, H_{1}^{P}\right\rangle, \cdots,\left\langle u_{n}, H_{n}^{P}\right\rangle\right)=\Delta\left(\sum_{j=1}^{n} w_{j} \Delta^{-1}\left(H^{P}\right)\right)=\Delta\left(\Delta^{-1}\left(H^{P}\right)\right) .
$$

Especially, if $s_{k i}=s_{\alpha}$ for all $i, k$, then $H_{i}^{P}=\left\{\left(s_{\alpha}, 1\right)\right\}$ and the IHFLPOWA operator is reduced to the ILOWA operator, i.e.,

$$
\operatorname{IHFLPOWA}\left(\left\langle u_{1}, H_{1}^{P}\right\rangle, \cdots,\left\langle u_{n}, H_{n}^{P}\right\rangle\right)=\operatorname{ILOWA}\left(\left\langle u_{1}, s_{\alpha}\right\rangle, \cdots,\left\langle u_{n}, s_{\alpha}\right\rangle\right)=\Delta\left(\sum_{j=1}^{n} w_{j} \Delta^{-1}\left(s_{\alpha}\right)\right)=s_{\alpha}
$$

By choosing different weighting vectors, the IHFLPOWA operator defined by (11) has different reductions, which are described as follows.

Property 1 In the IHFLPOWA operator, we have the following three reduced linguistic aggregation operators.

1. If $W=\left(\frac{1}{n}, \cdots, \frac{1}{n}\right)$, then the IHFLPOWA operator is reduced to the hesitant fuzzy linguistic arithmetic mean probability averaging (HFLMPA) operator, i.e.,

$$
\operatorname{HFLMPA}\left(\left\langle u_{1}, H_{1}^{P}\right\rangle, \cdots,\left\langle u_{n}, H_{n}^{P}\right\rangle\right)=\Delta\left(\sum_{j=1}^{n} \frac{1}{n} \Delta^{-1}\left(H_{j}^{P}\right)\right)=\Delta\left(\frac{1}{n} \sum_{i=1}^{n} \sum_{k=1}^{l_{i}} p_{k i} \Delta^{-1}\left(s_{k i}\right)\right) \text {. }
$$

2. If $P_{i}$ is a uniform distribution for all $i$, i.e., $P_{i}=\left(\frac{1}{l_{i}}, \frac{1}{l_{i}}, \cdots, \frac{1}{l_{i}}\right)$ then the induced hesitant fuzzy linguistic probabilistic mean ordered weighted averaging (IHFLPMOWA) operator can 
be obtained as follows:

$$
\begin{aligned}
& \operatorname{IHFLPMOWA}\left(\left\langle u_{1}, H_{1}^{P}\right\rangle, \cdots,\left\langle u_{n}, H_{n}^{P}\right\rangle\right)=\Delta\left(\sum_{j=1}^{n} w_{j} \Delta^{-1}\left(H_{j}^{P}\right)\right)=\Delta\left(\sum_{j=1}^{n}\left(w_{j} \sum_{k=1}^{l_{j}}\left(\frac{1}{l_{j}} \Delta^{-1}\left(s_{k j}\right)\right)\right)\right) \\
& =\Delta\left(\sum_{j=1}^{n} \frac{w_{j}}{l_{j}}\left(\sum_{k=1}^{l_{j}} \Delta^{-1}\left(s_{k j}\right)\right)\right) .
\end{aligned}
$$

3. If $w_{i}=\frac{1}{n}$ and $p_{k i}=\frac{1}{l_{i}}$ for all $k$, $i$, then the IHFLPOWA operator will reduce to the hesitant fuzzy linguistic arithmetic mean probabilistic mean averaging (HFLMPMA) operator, i.e.,

$$
\begin{array}{r}
\operatorname{HFLMPMA}\left(\left\langle u_{1}, H_{1}^{P}\right\rangle, \cdots,\left\langle u_{n}, H_{n}^{P}\right\rangle\right)=\Delta\left(\sum_{j=1}^{n} \frac{1}{n} \Delta^{-1}\left(H_{j}^{P}\right)\right) \\
=\Delta\left(\sum_{i=1}^{n}\left(\frac{1}{n} \sum_{k=1}^{l_{i}}\left(\frac{1}{l_{i}} \Delta^{-1}\left(s_{k i}\right)\right)\right)\right)=\Delta\left(\sum_{i=1}^{n} \frac{1}{n l_{i}}\left(\sum_{k=1}^{l_{i}} \Delta^{-1}\left(s_{k i}\right)\right)\right) .
\end{array}
$$

Property 2 If $w_{j}=1$ and $w_{i}=0$ for $i \neq j$, then the IHFLPOWA operator defined by (11) reduces to the linguistic probabilistic aggregation (LPA) of $H_{i}^{P}$ with the $j$ th largest $u_{i}$, i.e.,

$$
\begin{gathered}
\operatorname{IHFLPOWA}\left(\left\langle u_{1}, H_{1}^{P}\right\rangle, \cdots,\left\langle u_{n}, H_{n}^{P}\right\rangle\right)=\Delta\left(\sum_{j=1}^{n}\left(w_{j} \sum_{k=1}^{l_{j}}\left(p_{k j} \Delta^{-1}\left(s_{k j}\right)\right)\right)\right) \\
=\Delta\left(\Delta^{-1}\left(H_{i}^{P}\right)\right)=\Delta\left(\sum_{k=1}^{l_{i}}\left(p_{k i} \Delta^{-1}\left(s_{k i}\right)\right)\right) .
\end{gathered}
$$

Corollary 1 The maximum-IHFLPOWA operator is obtained if $\Delta^{-1}\left(H_{i}^{P}\right)=\max \left\{\Delta^{-1}\left(H_{j}^{P}\right) j=1, \cdots, n\right\}$. The minimum-IHFLPOWA operator is obtained if $\Delta^{-1}\left(H_{i}^{P}\right)=\min \left\{\Delta^{-1}\left(H_{j}^{P}\right) j=1, \cdots, n\right\}$.

Property 3 If there is only one linguistic term $s_{\alpha_{i}}$ in each hesitant fuzzy linguistic term set such that $p_{l_{(i)} i}=1$, i.e., $H_{i}^{P}=\left\{\left(s_{\alpha_{1}}, 0\right), \cdots,\left(s_{\alpha_{i}}, 1\right), \cdots,\left(s_{\alpha_{l_{i}}}, 0\right)\right\}$, then the IHFLPOWA operator defined by (11) is reduced to the induced linguistic OWA.

Based on Theorem 1 and Properties 1-3, we notice that there are many interesting advantages of the IHFLPOWA operator defined by (11), such as monotonicity, boundary and idempotency, furthermore, it is the extensions of many others linguistic aggregation operators (12)-(15). According to (11), we also notice that there are many disadvantages of the IHFLPOWA operator, such as there needs more information than others linguistic aggregation operators, i.e., weighting information, probability information and the order inducing variable are needed in the IHFLPOWA operator, naturally, its computation is more complex than others linguistic aggregation operators.

\subsection{The Measures for Characterizing the Weighting Vector}

The measures are used to characterize the weighting vectors of aggregation operators [49, 50], such as the degrees of orness and andness (also called as the attitudinal character), the entropy 
of dispersion, etc. According to Eq.(11), the measures of the IHFLPOWA operator are decided by the weighting vector and probability distribution of each hesitant fuzzy linguistic term set. Denote $s_{\alpha}=\min \left\{H_{i^{-}}^{P} \mid i=1, \cdots, n\right\}$ and $s_{\beta}=\max \left\{H_{i^{+}}^{P} \mid i=1, \cdots, n\right\}$. For convenience, we rewrite each hesitant fuzzy linguistic term set with probabilistic information as $H_{i}^{P}=\left\{\left(s_{\alpha}, p_{\alpha i}\right), \cdots,\left(s_{\beta}, p_{\beta i}\right)\right\}$ such that $\sum_{l=\alpha}^{\beta} p_{l_{i}}=1$ where $p_{l_{i}}=0$ means $s_{l} \notin H_{i}^{P}$ and $\mathrm{s}_{l} \in S^{\prime}=\left\{\mathrm{s}_{\alpha}, \mathrm{s}_{\alpha+1}, \cdots, \mathrm{s}_{\beta}\right\}$, such as in Example 1,

$$
H_{1}^{P}=\left\{\left(s_{2}, 0.5\right),\left(s_{3}, 0.3\right),\left(s_{4}, 0.2\right),\left(s_{5}, 0\right),\left(s_{6}, 0\right),\left(s_{7}, 0\right)\right\} .
$$

Then the IHFLPOWA operator can be rewritten as follows:

$$
\begin{array}{r}
\operatorname{IHFLPOWA}\left(\left\langle u_{1}, H_{1}^{P}\right\rangle, \cdots,\left\langle u_{n}, H_{n}^{P}\right\rangle\right)=\Delta\left(\sum_{j=1}^{n} w_{j} \Delta^{-1}\left(H_{j}^{P}\right)\right) \\
=\Delta\left(\sum_{j=1}^{n} w_{j}\left(\sum_{l=\alpha}^{\beta} p_{l j} \Delta^{-1}\left(s_{l}\right)\right)\right)=\Delta\left(\sum_{l=\alpha}^{\beta}\left(\left(\sum_{j=1}^{n}\left(w_{j} p_{l j}\right)\right) \times l\right)\right) .
\end{array}
$$

Denote $\omega_{l}=\sum_{j=1}^{n}\left(w_{j} p_{l j}\right)$, where $p_{l_{j}}$ is the probability of $s_{l}$ in $H_{i}^{P}$ with the $j$ th largest $u_{i}$, then the weight of $s_{l}$ in the IHFLPOWA operator is $\omega_{l}$ and $\omega_{l}=0,0 \leq l<\alpha, \beta<l \leq g$ and IHFLPOWA operator is furthermore rewritten as follows:

$$
\operatorname{IHFLPOWA}\left(\left\langle u_{1}, H_{1}^{p}\right\rangle, \cdots,\left\langle u_{n}, H_{n}^{p}\right\rangle\right)=\Delta\left(\sum_{l=\alpha}^{\beta} \omega_{l} \times l\right)=\Delta\left(\sum_{l=\alpha}^{\beta} \omega_{\beta+\alpha-l} \times(\beta+\alpha-l)\right) \text {. }
$$

Based on (16) and (17), the degree of orness associated with the IHFLPOWA operator is calculated as follows:

$$
\begin{aligned}
\text { orness } & \text { IHFLPOWA })=\sum_{l=\alpha}^{\beta} \omega_{\beta+\alpha-l} \frac{(\beta-\alpha+1)-(l-\alpha+1)}{\beta-\alpha} \\
= & \sum_{l=\alpha}^{\beta} \omega_{\beta+\alpha-l} \frac{\beta-l}{\beta-\alpha} .
\end{aligned}
$$

Based on Yager's works [49], if $\omega_{\alpha}=1$, then the IHFLPOWA operator is a pure "and" operator. If $\omega_{\beta}=1$, then the IHFLPOWA operator is a pure "or" operator. The more close all the total weight is to $\omega_{\alpha}$, the closer the IHFLPOWA operator is a pure "and" operator. The more close all the total weight is to $\omega_{\beta}$, the more close the IHFLPOWA operator is a pure "or" operator. Formally, the measure of "andness" is the complement of the "orness", for the IHFLPOWA operator, we have andness (IHFLPOWA)= 1-orness (IHFLPOWA). According to Eq. (18), orness(IHFLPOWA) has the following properties.

Property4 For any IHFLPOWA operator, if $w_{j}=1$ and $w_{i}=0(i \neq j)$, then orness(IHFLPOWA) defined by (18) is reduced as orness for the linguistic probabilistic aggregation operator of $H_{i}^{P}$ with the $j$ th largest $u_{i}$, i.e.,

$$
\text { orness (IHFLPOWA) }=\sum_{l=\alpha}^{\beta}\left(\sum_{j=1}^{n} w_{j} p_{\beta+\alpha-l, j}\right) \frac{\beta-l}{\beta-\alpha}=\sum_{l=\alpha}^{\beta} p_{\beta+\alpha-l, i} \frac{\beta-l}{\beta-\alpha} .
$$


1. If $p_{l_{i}}=\frac{1}{\beta+\alpha-l}(l=\alpha, \alpha+1, \cdots, \beta)$, then

$$
\operatorname{orness}(\text { IHFLPOWA })=\sum_{l=\alpha}^{\beta}\left(\frac{\beta-l}{\beta-\alpha} \times \frac{1}{\beta-\alpha+1}\right)=\frac{1}{2} .
$$

In this case, the IHFLPOWA operator is reduced as the linguistic mean operator of $H_{j}^{P}$, i.e.,

$$
\operatorname{IHFLPOWA}\left(\left\langle u_{1}, H_{1}^{P}\right\rangle, \cdots,\left\langle u_{n}, H_{n}^{P}\right\rangle\right)=\Delta\left(\sum_{l=\alpha}^{\beta} \frac{l}{\beta-\alpha+1}\right)=\Delta\left(\frac{\alpha+\beta}{2}\right) ;
$$

2. If $p_{\alpha_{i}}=1$, then orness(IHFLPOWA) $=1 \times \frac{\beta-\beta}{\beta-\alpha}=0$. in this case,the IHFLPOWA operator is reduced as the linguistic min operator of $H_{i}^{P}$ with the $j$ th largest $u_{i}$ i.e.,

$$
\operatorname{IHFLPOWA}\left(\left\langle u_{1}, H_{1}^{P}\right\rangle, \cdots,\left\langle u_{n}, H_{n}^{P}\right\rangle\right)=\Delta(\min \{\alpha, \cdots, \beta\})=s_{\alpha} ;
$$

3. If $p_{\beta_{i}}=1$, then orness(IHFLPOWA $)=1 \times \frac{\beta-\alpha}{\beta-\alpha}=1$. in this case, the IHFLPOWA operator is reduced as the linguistic max operator of $H_{i}^{P}$ with the $j$ th largest $u_{i}$ i.e.,

$$
\operatorname{IHFLPOWA}\left(\left\langle u_{1}, H_{1}^{P}\right\rangle,\left\langle u_{2}, H_{2}^{P}\right\rangle, \cdots,\left\langle u_{n}, H_{n}^{P}\right\rangle\right)=\Delta(\max \{\alpha, \cdots, \beta\})=s_{\beta} .
$$

Intuitively, Property 4 explains that if $w_{j}=1$ and $w_{i}=0(i \neq j)$, then the bigger the value of orness(IHFLPOWA), the closer that the aggregation result is to the maximum; The smaller the value of orness(IHFLPOWA), the closer that the aggregation result is to the minimum. Property5 If $\forall l, i, p_{l i}=\frac{1}{\beta-\alpha+1}$, then $\omega_{l}=\sum_{j=1}^{n} w_{j} p_{l j}=\frac{1}{\beta-\alpha+1} \sum_{j=1}^{n} w_{j}=\frac{1}{\beta-\alpha+1}$ and

$$
\operatorname{Orness}(\text { IHFLPOWA })=\sum_{l=a}^{\beta} \omega_{\beta+\alpha-l} \frac{\beta-l}{\beta-\alpha}=\frac{1}{\beta-\alpha+1} \sum_{l=\alpha}^{\beta} \frac{\beta-l}{\beta-\alpha}=\frac{1}{2} .
$$

Inspired by Yager's works [47], the entropy of dispersion for the IHFLPOWA operator can be represented as follows.

$$
H(\text { IHFLPOWA })=-\sum_{l=\alpha}^{\beta} \omega_{l} \ln \omega_{l} .
$$

To measure the divergence of the weights against the degree of orness-andness measure [51], the divergence of the weights for the IHFLPOWA operator can be represented as follows.

$$
\operatorname{Div}(\text { IHFLPOWA })=\sum_{l=\alpha}^{\beta} \omega_{\beta+\alpha-l}\left(\frac{\beta-l}{\beta-\alpha}-\text { orness }(\text { IHFLPOWA })\right)^{2}
$$

To measure the degree of balance between favoring the higher-valued elements or lower-valued elements [52], we represent the balance of the IHFLPOWA operator as follows.

$\operatorname{Bal}($ IHFLPOWA $)=\sum_{l=\alpha}^{\beta} \omega_{\beta+\alpha-l} \frac{\beta-\alpha+2-2(l-\alpha+1)}{\beta-\alpha}=\sum_{l=\alpha}^{\beta} \omega_{\beta+\alpha-l} \frac{\beta+\alpha-2 l}{\beta-\alpha}$. 
According to (16) and (17), these measures have some particular cases as follows.

Property 6 For the IHFLPOWA operator, we have

1. If $w_{j}=1, w_{i}=0(i \neq j)$ and $p_{\beta_{j}}=1$, i.e., the probability $p_{\beta_{i}}$ of $s_{\beta}$ in $H_{i}^{P}$ with the $j$ th largest $u_{i}$ is 1 ,then $\omega_{\beta}=1$ and $\omega_{l}=0(l \neq \beta)$, which means that the aggregated result is the maximum $s_{\beta}$, in which, orness(IHFLPOWA) $=1, H($ IHFLPOWA $)=0, \operatorname{Div}($ IHFLPOWA $)=0$ and $B a l($ IHFLPOWA $)=1$.

2. If $w_{j}=1, w_{i}=0(i \neq j)$ and $p_{\alpha_{j}}=1$, i.e., the probability $p_{\alpha_{i}}$ of $s_{\alpha}$ in $H_{i}^{P}$ with the $j$ th largest $u_{i}$ is 1 ,then $w_{\alpha}=1$ and $w_{\alpha}=0(l \neq \alpha)$, the aggregated result is the minmum $s_{\alpha}$, in which, $\quad$ orness $($ IHFLPOWA $)=0, \quad H($ IHFLPOWA $)=0, \quad \operatorname{Div}($ IHFLPOWA $)=0 \quad$ and $\operatorname{Bal}(\mathrm{IHFLPOWA})=-1$.

3. If $W=\left(\frac{1}{n}, \frac{1}{n}, \cdots, \frac{1}{n}\right)$ and $\sum_{i=1}^{n} p_{l i}=\frac{n}{\beta-\alpha+1}$ for all $l(l \in\{\alpha, \alpha+1, \cdots, \beta\})$, then $\omega_{l}=\sum_{j=1}^{n} w_{j} p_{l_{j}}=\frac{1}{n} \times \frac{n}{\beta-\alpha+1}=\frac{1}{\beta-\alpha+1}$ for all $l$, in which, orness(IHFLPOWA) $=\frac{1}{2}$, $H($ IHFLPOWA $)=\ln (\beta-\alpha+1), \operatorname{Div}($ IHFLPOWA $)=\frac{1}{6(\beta-\alpha)}+\frac{1}{12}$ and $\operatorname{Bal}($ IHFLPOWA $)=0$.

\section{Illustrative Case Study}

In this section, as an example, we consider a movie fuzzy ontology creation based on the IHFLPOWA operator, which is initially described in [4]: A company, such as Film affinity, is interested in building a movie fuzzy ontology using the opinions of their users. In such a way, it can be consulted by users in order to find films that correspond to their interests. The company wants to classify 20 different movies (alternatives) $A=\left\{A_{1}, A_{2}, \cdots, A_{20}\right\}$ using the four following concepts $C=\left\{c_{1}, c_{2}, c_{3}, c_{4}\right\}$ :

1. Action $\left(c_{1}\right)$ : Measures the amount of action in the film;

2. Humor $\left(c_{2}\right)$ : Takes into account if the film is comical;

3. Drama $\left(c_{3}\right)$ : Refers to whether the film storyline is sad and touching;

4. Mystery $\left(c_{4}\right)$ : Mystery films get high label values in this concept.

It should be noted that this is a brief movie fuzzy ontology example. Other concepts like argument, overall opinion, actors' performance, science fiction or horror could be added. Creating a functional movie fuzzy ontology is out of the scope of this article.

Because four concepts need to be measured using users' opinion, four different group decision making processes must be performed, such as for the action concept, users are asked to sort the films according to the level of action on them. Because a large amount of individuals are available, it is difficult for experts to carry out a pairwise comparison of all of them. In this example, a group decision making method that allows the participation of a large amount of experts and a high number of alternatives is followed. This method allows users to provide information only about the movies that they prefer. In such a way, a user chooses for 
themselves how many pairwise comparisons they wish to make. Because participation from a large number of users is expected, enough information to carry out a reliable group decision making process will be collected. Formally, in a movie fuzzy ontology $O_{F}=\{I, C, R, F, A\}$, assume individuals (movies) are $I=\left\{A_{1}, A_{2}, \cdots, A_{n}\right\}$, concepts associated with movies are $C=\left\{C_{1}, C_{2}, \cdots, C_{m}\right\}$ and users are $E=\left\{e_{1}, e_{2}, \cdots, e_{p}\right\}$, users provide their opinion about movies by using hesitant fuzzy linguistic term set with probabilistic information on a linguistic term set, then creating the movie fuzzy ontology based on the IHFLPOWA operator can be described as following steps:

Step 1. Let a linguistic term set be $S=\left\{s_{0}, s_{1}, \cdots, s_{g}\right\}$. User $e_{q}$ provides his/her opinion matrix: $H^{P(q)}=\left(H_{t i}^{P(q)}\right)_{n \times m}$, where $H_{t i}^{P(q)}$ indicates the hesitant fuzzy linguistic term set with probabilistic information provided by user $e_{q}$ for the alternative $A_{t}$ with respect to the concept $C_{i}$ and each $H_{t i}^{P(q)}=\left\{s_{t i 1}^{(q)}, s_{t i 2}^{(q)}, \cdots, s_{t i l_{i i}}^{(q)}\right\}, l_{t i}=\left|H_{t i}^{P(q)}\right|$. Assume the weighting information about users are $V=\left(v_{1}, v_{2}, \cdots, v_{p}\right)$ satisfying that $\sum_{q=1}^{P} v_{q}=1$ and $0 \leq v_{q} \leq 1$. Let the probabilistic weighting vector provided by the user $e_{q}$ for the hesitant fuzzy linguistic term set $H_{t i}^{P(q)}$ be $H_{t i}^{P(q)}=\left\{p_{t i 1}^{(q)}, p_{t i 2}^{(q)}, \cdots, p_{t i l_{i}}^{(q)}\right\}$ such that $\sum_{k=1}^{l_{i i}} p_{t i k}^{(q)}=1$ and $0 \leq p_{t i k}^{(q)} \leq 1$.

Step 2. Assume the inducing variables $U=\left(u_{1}, u_{2}, \cdots, u_{p}\right)$. For the alternative $A_{t}$ and concept $C_{i}$, we aggregate all $H_{t i}^{P(q)}(i=1,2, \cdots, m)$ into an individual overall result by using the IHFLPOWA operator, i.e., the aggregation results of all users for alternative $A_{t}$ with respect to $C_{i}$ is a 2-tuple linguistic value $\left(s_{t}^{(q)}, \alpha_{t}^{(q)}\right)$.

Step 3. Rank the $n$ alternatives according to their results $\left(s_{t}^{(q)}, \alpha_{t}^{(q)}\right)(t=1,2, \cdots, n)$ with respect to each concept $C_{i}, R$ and $F$ are obtained and the fuzzy ontology is constructed.

This example focuses on preferences provided by a set of four users $E=\left\{e_{1}, e_{2}, e_{3}, e_{4}\right\}$. Each user provides his/her opinion about 4 movies according to the four concepts $C=\left\{c_{1}, C_{2}, C_{3}, C_{4}\right\}$ by using the hesitant fuzzy linguistic term sets on $S=\left\{s_{0}=E L, s_{1}=V L, s_{2}=L, s_{3}=S L, s_{4}=M, s_{5}=S H, s_{6}=H, s_{7}=V H, s_{8}=E H\right\}$ with probabilistic information. The specific process can be described in the following:

Step 1. Assume that $V=(0.3,0.2,0.2,0.3)$. Each user $e_{q}$ provides its opinion $H_{t i}^{P(q)}$ for movie $A_{t}$ concerning concept $C_{i}$ in the form of hesitant fuzzy linguistic term sets on $S$, the first four movies of which are shown in Table 1, in which, $H^{P(1)}$ is evaluation linguistic matric of the first four movies $\left\{A_{1}, A_{2}, A_{3}, A_{4}\right\}$ concerning the four concepts $C=\left\{c_{1}, C_{2}, C_{3}, C_{4}\right\}$ provided by user $e_{1}$, such as $H_{34}^{P(1)}=\left\{s_{6}, s_{7}\right\}$ means that user $e_{1}$ evaluates movie $A_{3}$ with respect to concept $C_{4}$ by using the hesitant fuzzy linguistic term set $\left\{s_{6}, s_{7}\right\}$. Similarly, users $e_{2}, e_{3}$ and $e_{4}$ provide evaluation linguistic matrix $H^{P(2)}, H^{P(3)}$ and $H^{P(4)}$ for the first four movies $\left\{A_{1}, A_{2}, A_{3}, A_{4}\right\}$ concerning the four concepts $C=\left\{C_{1}, C_{2}, C_{3}, C_{4}\right\}$, respectively. 
Table 1. Evaluation linguistic information of the first four movies provided by four users

\begin{tabular}{|c|c|c|c|c|c|}
\hline & & $c_{1}$ & $c_{2}$ & $c_{3}$ & $c_{4}$ \\
\hline$H^{P(1)}$ & $\begin{array}{l}A_{1} \\
A_{2} \\
A_{3} \\
A_{4}\end{array}$ & 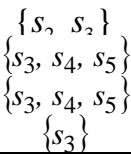 & $\begin{array}{c}\left\{s_{1}, s_{2}, s_{3}\right\} \\
\left\{\begin{array}{c}s_{5} \\
s_{3}\end{array}\right\} \\
\left\{s_{4}, s_{5}\right\}\end{array}$ & $\begin{array}{c}\left\{s_{-}\right\} \\
\left\{s_{2} s_{3}\right\} \\
\left\{s_{3}\right\} \\
\left\{s_{5}\right\}\end{array}$ & $\begin{array}{l}\left\{s_{6}, s_{7}\right\} \\
\left\{s_{3}, s_{1}\right\} \\
\left\{s_{c}, s_{7}\right\} \\
\left\{s_{7}, s_{8}\right\}\end{array}$ \\
\hline$H^{P(2)}$ & $\begin{array}{l}\mathrm{A}_{1} \\
\mathrm{~A}_{2} \\
\mathrm{~A}_{3} \\
\mathrm{~A}_{4}\end{array}$ & $\begin{array}{c}\left\{s_{4}, s_{5}, s_{6}\right\} \\
\left\{s_{6}, s_{7}\right\} \\
\left\{s_{6}\right\} \\
\left\{s_{5}, s_{6}\right\} \\
\end{array}$ & $\left.\begin{array}{l}\left\{s_{6}, s_{7}\right\} \\
s_{7}, s_{8} \\
\left\{s_{4}, s_{5}\right. \\
\left\{s_{4}, s_{5}\right.\end{array}\right\}$ & $\begin{array}{r}\left\{s_{4}, s_{5}, s_{6}\right. \\
\left\{s_{6}, s_{7}\right\} \\
\left\{s_{4}, s_{5}\right\} \\
\left\{s_{3}, s_{4}\right\}\end{array}$ & $\begin{array}{c}\left\{s_{4}, s_{5}, s_{6}\right. \\
\left\{s_{3}, s_{4}, s_{5}\right. \\
\left\{s_{2 .} s_{3}\right\} \\
\left\{s_{5}, s_{6}\right\}\end{array}$ \\
\hline$H^{P(3)}$ & $\begin{array}{l}\mathrm{A}_{1} \\
\mathrm{~A}_{2} \\
\mathrm{~A}_{3} \\
\mathrm{~A}_{4}\end{array}$ & $\begin{array}{c}\left\{s_{5}\right\} \\
\left\{s_{1}, s_{2}, s_{3}\right\} \\
\left\{s_{6}, s_{7}\right\} \\
\left\{s_{7}\right\} \\
\end{array}$ & $\begin{array}{c}\begin{array}{c}\left\{s_{6}, s_{7}, s_{8}\right\} \\
\left.s_{4}, s_{5}, s_{6}\right\} \\
\left\{s_{7}\right\}\end{array} \\
\left\{s_{6}, s_{7}\right\} \\
\end{array}$ & $\begin{array}{c}\left\{\begin{array}{c}\left\{s_{6}, s_{7}\right\} \\
\left\{s_{4}\right\}\end{array}\right. \\
\left\{\begin{array}{c}\left\{s_{6}, s_{7}\right\} \\
\left.s_{4}, s_{5}\right\}\end{array}\right.\end{array}$ & $\begin{array}{c}\left\{s_{4}, s_{5}, s_{6}\right. \\
\left\{s_{3}, s_{4}\right\} \\
\left\{s_{4}\right\} \\
\left\{s_{5}, s_{6}\right\} \\
\end{array}$ \\
\hline$H^{P(4)}$ & $\begin{array}{l}A_{1} \\
A_{2} \\
A_{3} \\
A_{4}\end{array}$ & $\begin{array}{c}\left\{s_{2} . s_{3}\right\} \\
\left\{s_{2}\right\} \\
\left\{s_{2}\right\} \\
\left\{s_{2}, s_{3}\right\}\end{array}$ & $\begin{array}{c}\left\{s_{4}\right\} \\
\left\{s_{2}, s_{3}\right\} \\
\left\{s_{2}, s_{3}, s_{4}\right\} \\
\left\{s_{3}, s_{4}, s_{5}\right\}\end{array}$ & $\begin{array}{c}\left\{s_{2}, s_{3}, s_{4}\right. \\
\left\{s_{3}, s_{4}\right\} \\
\left\{s_{4}\right\} \\
\left\{s_{4}, s_{5}\right\}\end{array}$ & $\begin{array}{c}\left\{s_{3}\right\} \\
\left\{s_{1}, s_{2}, s_{3}\right\} \\
\left\{s_{6}, s_{7}\right\} \\
\left\{s_{7}, s_{8}\right\}\end{array}$ \\
\hline
\end{tabular}

Furthermore, each user $e_{q}$ provides its probabilistic vector $\left(p_{t i 1}^{(q)}, p_{t i 2}^{(q)}, \cdots, p_{t i l_{i}}^{(q)}\right)$ for $P_{t i}^{P(q)}$ shown in Table 2, in which, $P_{t i}^{P(1)}$ is probabilistic information of evaluation linguistic terms of the first four movies $\left\{A_{1}, A_{2}, A_{3}, A_{4}\right\}$ concerning the four concepts $C=\left\{C_{1}, C_{2}, C_{3}, C_{4}\right\}$ provided by user $e_{1}$, such as $P_{34}^{P(1)}=(0.7,0.3)$ means that probabilistic information of the hesitant fuzzy linguistic term set $\left\{s_{6}, s_{7}\right\}$ is $(0.7,0.3)$, i.e., user $e_{1}$ provides $\left\{s_{6}, s_{7}\right\}$ to evaluate movie $A_{3}$ with respect to concept $C_{4}$, more important, user $e_{1}$ prefers to use $s_{6}$ (with possibility 0.7 ) than $S_{7}$ (with possibility 0.3). Similarly, $P_{t i}^{P(2)}, P_{t i}^{P(3)}$ and $P_{t i}^{P(4)}$ are probabilistic information of evaluation linguistic terms of the first four movies $\left\{A_{1}, A_{2}, A_{3}, A_{4}\right\}$ concerning the four concepts $C=\left\{c_{1}, c_{2}, C_{3}, c_{4}\right\}$ provided by users $e_{2}, e_{3}$ and $e_{4}$, respectively.

Table 2. The probabilistic vectors of the first four movies provided by four users.

\begin{tabular}{cccccc}
\hline & & $c_{1}$ & $c_{2}$ & $c_{3}$ & $c_{4}$ \\
\hline \multirow{3}{*}{$P_{t i}^{P(1)}$} & $\mathrm{A}_{1}$ & $(0.9,0.1)$ & $(0.2,0.3,0.5)$ & $(1)$ & $(0.4,0.6)$ \\
& $\mathrm{A}_{2}$ & $(0.4,0.3,0.3)$ & $(1)$ & $(0.7,0.3)$ & $(0.3,0.7)$ \\
& $\mathrm{A}_{3}$ & $(0.4,0.4,0.2)$ & $(1)$ & $(1)$ & $(0.7,0.3)$ \\
& $\mathrm{A}_{4}$ & $(1)$ & $(0.4,0.6)$ & $(1)$ & $(0.7,0.3)$ \\
\hline \multirow{3}{*}{$P_{t i}^{P(2)}$} & $\mathrm{A}_{1}$ & $(0.4,0.3,0.3)$ & $(0.4,0.6)$ & $(0.4,0.3,0.3)$ & $(0.5,0.3,0.2)$ \\
& $\mathrm{A}_{2}$ & $(0.6,0.4)$ & $(0.3,0.7)$ & $(0.6,0.4)$ & $(0.2,0.6,0.2)$ \\
& $\mathrm{A}_{3}$ & $(1)$ & $(0.2,0.8)$ & $(0.5,0.5)$ & $(0.5,0.5)$ \\
& $\mathrm{A}_{4}$ & $(0.7,0.3)$ & $(0.4,0.6)$ & $(0.5,0.5)$ & $(0.8,0.2)$ \\
\hline \multirow{3}{*}{$P_{t i}^{P(3)}$} & $\mathrm{A}_{1}$ & $(1)$ & $(0.3,0.3,0.4)$ & $(0.6,0.4)$ & $(0.3,0.5,0.2)$ \\
& $\mathrm{A}_{2}$ & $(0.4,0.4,0.2)$ & $(0.1,0.4,0.5)$ & $(1)$ & $(0.2,0.8)$ \\
& $\mathrm{A}_{3}$ & $(0.5,0.5)$ & $(1)$ & $(0.8,0.2)$ & $(1)$ \\
& $\mathrm{A}_{4}$ & $(1)$ & $(0.8,0.2)$ & $(0.9,0.1)$ & $(0.4,0.6)$ \\
\hline \multirow{2}{*}{$P_{t i}^{P(4)}$} & $\mathrm{A}_{1}$ & $(0.5,0.5)$ & $(1)$ & $(0.5,0.3,0.2)$ & $(1)$ \\
& $\mathrm{A}_{2}$ & $(1)$ & $(0.3,0.7)$ & $(0.5,0.5)$ & $(0.2,0.7,0.1)$ \\
& $\mathrm{A}_{3}$ & $(1)$ & $(0.2,0.2,0.6)$ & $(1)$ & $(0.6,0.4)$ \\
& $\mathrm{A}_{4}$ & $(0.3,0.7)$ & $(0.3,0.4,0.3)$ & $(0.5,0.5)$ & $(0.6,0.4)$ \\
\hline
\end{tabular}


Step 2. Assume $U=(9,8,4,6)$. Since $u_{1}>u_{2}>u_{4}>u_{3}$, thus HFLTSs with probabilistic information can be listed as $H_{t 1}^{P(q)}>H_{t 2}^{P(q)}>H_{t 3}^{P(q)}>H_{t 4}^{P(q)}$ for all $t$,q. For each movie $A_{t}$ and concept $c_{i}$, the IHFLPOWA operator is used to aggregate the $H_{t i}^{P(q))}(i=1,2,3,4)$ into an individual overall value $\left(s_{t}^{(q)}, \alpha_{t}^{(q)}\right)$, such as for movie $\mathrm{A}_{1}$ and concept $\mathrm{c}_{1}$, we have $\operatorname{IHFLPOWA}\left(\left\langle u_{1}, H_{11}^{P(1)}\right\rangle, \cdots,\left\langle u_{4}, H_{14}^{P(1)}\right\rangle\right)$ $=\Delta(0.3 \times(0.9 \times 2+0.1 \times 3)+0.2 \times(0.4 \times 4+0.3 \times 5+0.3 \times 6)+0.2 \times(0.5 \times 2+0.5 \times 3)+0.3 \times 5)$ $=\Delta(3.61)=\left(s_{4},-0.39\right)$, that is, $\left(s_{1}^{(1)}, \alpha_{1}^{(1)}\right)=\left(s_{4},-0.39\right)$, it also means that four users $E=\left\{e_{1}, e_{2}, e_{3}, e_{4}\right\}$ provide $\left(s_{4},-0.39\right)$ to evaluate movie $A_{1}$ with respect to concept $c_{1}$. Similarly, we can obtain all evaluation results for each movie $A_{t}$ with respect to concept $c_{i}$, which are shown in Table 3 .

Table 3. Evaluation results of four movies provided by four users according to four concepts

\begin{tabular}{ccccc} 
& $c_{1}$ & $c_{2}$ & $c_{3}$ & $c_{4}$ \\
\hline $\mathrm{A}_{1}$ & $\left(s_{4},-0.39\right)$ & $\left(s_{3}, 0.43\right)$ & $\left(s_{5},-0.31\right)$ & $\left(s_{5},-0.01\right)$ \\
$\mathrm{A}_{2}$ & $\left(s_{5},-0.06\right)$ & $\left(s_{5}, 0.2\right)$ & $\left(s_{5},-0.36\right)$ & $\left(s_{3}, 0.25\right)$ \\
$\mathrm{A}_{3}$ & $\left(s_{4}, 0.34\right)$ & $\left(s_{4},-0.13\right)$ & $\left(s_{4}, 0.46\right)$ & $\left(s_{5},-0.13\right)$ \\
$\mathrm{A}_{4}$ & $\left(s_{4}, 0.17\right)$ & $\left(s_{5}, 0.05\right)$ & $\left(s_{4}, 0.33\right)$ & $\left(s_{6}, 0.39\right)$ \\
\hline
\end{tabular}

Step 3. Rank movies. According to Table 3, we can rank the first four movies $\left\{A_{1}, A_{2}, A_{3}, A_{4}\right\}$ with respect to each concept $c_{i}$, such as for concept $c_{1}$, we obtain $A_{2} \succ A_{3} \succ A_{4} \succ A_{1}$. Similarly, we can obtain the ranking of movies with respect to each concept $c_{i}$, and the movie fuzzy ontology is constructed, i.e., all rankings of movies with respect to concepts, respectively. Table 4 shows the first four movies fuzzy ontology, in which, for each concept $c_{i}$, the ranking of four movies is from top to down.

Table 4. The constructed movie fuzzy ontology of four movies based on IHFLPOWA operator

\begin{tabular}{ccccc}
\hline & \multicolumn{2}{c}{$\mathrm{R}$} & \\
\hline & $c_{1}$ & $c_{2}$ & $C_{2}$ & $c_{4}$ \\
The first four & $\mathrm{A}_{2}$ & $\mathrm{~A}_{2}$ & $\mathrm{~A}_{1}$ & $\mathrm{~A}_{4}$ \\
movies fuzzy & $\mathrm{A}_{3}$ & $\mathrm{~A}_{4}$ & $\mathrm{~A}_{2}$ & $\mathrm{~A}_{1}$ \\
ontology & $\mathrm{A}_{4}$ & $\mathrm{~A}_{3}$ & $\mathrm{~A}_{3}$ & $\mathrm{~A}_{3}$ \\
& $\mathrm{~A}_{1}$ & $\mathrm{~A}_{1}$ & $\mathrm{~A}_{4}$ & $\mathrm{~A}_{2}$ \\
\hline
\end{tabular}

Theoretically, the movie fuzzy ontology can be constructed by using different linguistic aggregation operator, in this paper, we focus on the max-IHFLPOWA, min-IHFLPOWA, HFLMPA, IHFLPMOWA and HFLMPMA operators to create the movie fuzzy ontology, for example, we utilize the max-IHFLPOWA operator to aggregate $H_{1 i}^{P(1)}(i=1,2,3,4)$ into an individual overall value $\left(s_{1}^{(1)}, \alpha_{1}^{(1)}\right)$ for the first four movie and concepts, i.e., 


$$
\begin{aligned}
& \max \text { IHFLPOWA }\left(\left\langle u_{1}, H_{11}^{P(1)}\right\rangle, \cdots,\left\langle u_{4}, H_{14}^{P(1)}\right\rangle\right) \\
& =\Delta(\max \{0.9 \times 2+0.1 \times 3,0.4 \times 4+0.3 \times 5+0.3 \times 6,0.5 \times 2+0.5 \times 3,5\})=\Delta(\max \{2.1,4.9,2.5,5\}) \\
& =\Delta(5)=s_{5} .
\end{aligned}
$$

It means that evaluation result of movie $A_{1}$ with respect to concept $c_{1}$ provided by four users $E=\left\{e_{1}, e_{2}, e_{3}, e_{4}\right\}$ is $s_{5}$, after all evaluation results of movies with respect to concepts are calculated by the max-IHFLPOWA operator, we can construct the movie fuzzy ontology, which is based on the max-IHFLPOWA operator. The first four movies fuzzy ontology based on the max-IHFLPOWA operator and others linguistic aggregation operators are shown in Table 5, in which, "Max" means that the first four movies fuzzy ontology is constructed by using the max-IHFLPOWA operator, "IHFLPMOWA" means that the first four movies fuzzy ontology is constructed by using the IHFLPMOWA operator, "Min" means that the first four movies fuzzy ontology is constructed by using the min-IHFLPOWA operator, "HFLMPMA" means that the first four movies fuzzy ontology is constructed by using the HFLMPMA operator, "HFLMPA" means that the first four movies fuzzy ontology is constructed by using the HFLMPA operator and "IHLPOWA" means that the first four movies fuzzy ontology is

\begin{tabular}{|c|c|c|c|c|c|c|c|c|c|}
\hline \multirow[t]{2}{*}{ Operat } & \multicolumn{4}{|c|}{ Ontology } & \multirow[t]{2}{*}{ Operator } & \multicolumn{4}{|c|}{ Ontology } \\
\hline & $c_{1}$ & $c_{2}$ & $c_{3}$ & $c_{4}$ & & $c_{1}$ & $c_{2}$ & $c_{3}$ & $c_{4}$ \\
\hline \multirow{4}{*}{ Max } & $\mathrm{A}_{4}$ & $A_{2}$ & $\mathrm{~A}_{2}$ & $\mathrm{~A}_{4}$ & \multirow{4}{*}{ IHFLPMOWA } & $A_{3}$ & $\mathrm{~A}_{2}$ & $\mathrm{~A}_{1}$ & $\mathrm{~A}_{4}$ \\
\hline & $\mathrm{A}_{3}$ & $\mathrm{~A}_{1}$ & $\mathrm{~A}_{3}$ & $\mathrm{~A}_{1}$ & & $A_{2}$ & $\mathrm{~A}_{4}$ & $A_{2}$ & $\mathrm{~A}_{1}$ \\
\hline & $\mathrm{A}_{2}$ & $\mathrm{~A}_{3}$ & $\mathrm{~A}_{1}$ & $\mathrm{~A}_{3}$ & & $\mathrm{~A}_{4}$ & $\mathrm{~A}_{3}$ & $\mathrm{~A}_{4}$ & $\mathrm{~A}_{2}$ \\
\hline & $\mathrm{A}_{1}$ & $\mathrm{~A}_{4}$ & $\mathrm{~A}_{4}$ & $\mathrm{~A}_{2}$ & & $\mathrm{~A}_{1}$ & $\mathrm{~A}_{1}$ & $A_{3}$ & $\mathrm{~A}_{3}$ \\
\hline \multirow{4}{*}{ Min } & $\mathrm{A}_{4}$ & $\mathrm{~A}_{4}$ & $\mathrm{~A}_{3}$ & $\mathrm{~A}_{4}$ & \multirow{4}{*}{ HFLMPMA } & $\mathrm{A}_{2}$ & $\mathrm{~A}_{2}$ & $\mathrm{~A}_{1}$ & $\mathrm{~A}_{4}$ \\
\hline & $\mathrm{A}_{1}$ & $\mathrm{~A}_{3}$ & $\mathrm{~A}_{4}$ & $\mathrm{~A}_{2}$ & & $\mathrm{~A}_{3}$ & $\mathrm{~A}_{4}$ & $\mathrm{~A}_{2}$ & $\mathrm{~A}_{3}$ \\
\hline & $\mathrm{A}_{3}$ & $A_{2}$ & $A_{2}$ & $\mathrm{~A}_{3}$ & & $\mathrm{~A}_{4}$ & $\mathrm{~A}_{1}$ & $\mathrm{~A}_{3}$ & $\mathrm{~A}_{1}$ \\
\hline & $\mathrm{A}_{2}$ & $\mathrm{~A}_{1}$ & $\mathrm{~A}_{1}$ & $\mathrm{~A}_{1}$ & & $\mathrm{~A}_{1}$ & $\mathrm{~A}_{3}$ & $\mathrm{~A}_{4}$ & $\mathrm{~A}_{2}$ \\
\hline \multirow{4}{*}{ HFLMPA } & $A_{2}$ & $\mathrm{~A}_{4}$ & $\mathrm{~A}_{1}$ & $\mathrm{~A}_{4}$ & \multirow{4}{*}{ IHLPOWA } & $\mathrm{A}_{2}$ & $A_{2}$ & $A_{1}$ & $\mathrm{~A}_{4}$ \\
\hline & $\mathrm{A}_{3}$ & $\mathrm{~A}_{2}$ & $\mathrm{~A}_{2}$ & $A_{1}$ & & $\mathrm{~A}_{3}$ & $\mathrm{~A}_{4}$ & $\mathrm{~A}_{2}$ & $A_{1}$ \\
\hline & $\mathrm{A}_{4}$ & $\mathrm{~A}_{3}$ & $\mathrm{~A}_{4}$ & $\mathrm{~A}_{3}$ & & $\mathrm{~A}_{4}$ & $\mathrm{~A}_{3}$ & $\mathrm{~A}_{3}$ & $\mathrm{~A}_{3}$ \\
\hline & $\mathrm{A}_{1}$ & $\mathrm{~A}_{1}$ & $\mathrm{~A}_{3}$ & $\mathrm{~A}_{2}$ & & $\mathrm{~A}_{1}$ & $\mathrm{~A}_{1}$ & $\mathrm{~A}_{4}$ & $\mathrm{~A}_{2}$ \\
\hline
\end{tabular}
constructed by using the IHLPOWA operator.

Table 5. The first four movies fuzzy ontologies based on six linguistic aggregation operators

In Table 5, we notice that six movies fuzzy ontologies are different each other, which are based on the max-IHFLPOWA, HFLMPA, IHFLPMOWA, HFLMPMA and IHFLPOWA operator, respectively. According to properties of linguistic aggregation operators, the first four movies fuzzy ontologies based on the max-IHFLPOWA operator and the minIHFLPOWA operator maybe correspond with optimistic and pessimistic users' knowledge, respectively. In addition, the HFLMPA, IHFLPMOWA, HFLMPMA and IHFLPOWA operators take into account probabilistic information in HFLTSs, their movies fuzzy ontologies may be more acceptive than others operators in real world practices. 


\section{Conclusions}

In this paper, we propose the IHFLPOWA operator to aggregate hesitant fuzzy linguistic terms with probability information, where each probability indicates the preference degree of linguistic term in the hesitant fuzzy linguistic term set. We analyze various interesting properties of the IHFLPOWA operator, which show that the IHFLPOWA operator is extensions of several existed linguistic aggregation operators. We design a method based on linguistic aggregation operators to create fuzzy ontologies when users utilize hesitant fuzzy linguistic terms to express their opinions with respect to concepts, an illustrative example of a movie fuzzy ontology is utilized to present the utility and efficiency of the IHFLPOWA operator, in addition, we compare with different linguistic aggregation operator to construct the movie fuzzy ontology.

\section{Acknowledgements}

This work has been partially supported by the National Natural Science Foundation of China (Grant No.61372187, 61702317, 61473239), the scientific and technological project of Sichuan Province (2016GZ0099), Development of Petroleum Equipment and Manufacturing Technology Science Foundation of Yan'an (Grant No. 2017WZZ-03-02) and D.S. Park's work is supported by MSIP (Ministry of Science, ICT and Future Planning), Korea, under the ITRC (Information Technology Research Center) support program (IITP-2017-2014-0-00720) supervised by the IITP (Institute for Information \& communications Technology Promotion) and the National Research Foundation of Korea (No. NRF-2017R1A2B1008421), and the Fundamental Research Funds for the Central Universities, China (GK201703059, GK201801004) as well as the Fund Program for the Scientific Activities of Selected Returned Overseas Professionals in Shaanxi Province (Grant No. 2017024).

\section{References}

[1] Mart'inez, L., "Rodriguez, R.M.; Herrera, F. The 2-tuple Linguistic Model-Computing with Words in Decision Making,” Springer International Publishing Switzerland, 2015. Article (CrossRef Link)

[2] Xu, Z.S., "Hesitant fuzzy sets theory, studies in fuzziness and soft computing," Springer, 2014. Article (CrossRef Link)

[3] Pei, Z.; Ruan, D.; Xu, Y., Liu, J., "Linguistic values-based intelligent information processing: Theory, methods, and applications," Atlantis Press, 2010. Article (CrossRef Link)

[4] Morente-Molinera, J.A., P'erez, I.J., Urẽna, M.R., Herrera-Viedma, E., "Creating knowledge databases for storing and sharing people knowledge automatically using group decision making and fuzzy ontologies," Inform. Sci., 328, 418-434, 2016. Article (CrossRef Link)

[5] Zadeh, L.A., "Fuzzy logic = computing with words," IEEE Trans. Fuzzy Syst., 4, 103-111, 1996. Article (CrossRef Link)

[6] Zadeh, L.A., "The concept of a linguistic variable and its applications to approximate reasoning-Part I, II, III,” Inform. Sci., 8, 9, 199-249, 1975. Article (CrossRef Link)

[7] Herrera, F., Martinez, L., "A 2-tuple fuzzy linguistic representation model for computing with words,” IEEE Trans. Fuzzy Syst., 8(6), 746-752, 2000. Article (CrossRef Link)

[8] Wang, J.H., Hao, J., "A new version of 2-tuple fuzzy linguistic representation model for computing with words,” IEEE Trans. Fuzzy Syst., 14(3), 435-445, 2006. Article (CrossRef Link) 
[9] Guo, W.T.; Huynh, V.N. et al, “A proportional 3-tuple fuzzy linguistic representation model for screening new product projects,” J. Syst. Sci. and Syst. Eng., 25(1), 1-22, 2016. Article (CrossRef Link)

[10] Dong, Y., Xu, Y., Yu, S., "Computing the numerical scale of the linguistic term set for the 2-tuple fuzzy linguistic representation,” IEEE Trans. Fuzzy Syst., 17(6), 1366-1378, 2009. Article (CrossRef Link)

[11] Li, D.F., "Multiattribute group decision making method using extended linguistic variables," Int. J. Uncertainty, Fuzziness and Knowl.-Based Syst., 17(6), 793-806, 2009. Article (CrossRef Link)

[12] Wei, G.W., "Extension of TOPSIS method for 2-tuple linguistic multiple attribute group decision making with incomplete weight information,” Knowl. Inf. Syst. 2010, 25, 623-634 2010. Article (CrossRef Link)

[13] Yang, W.E.; Wang, X.F., Wang, J.Q., “Counted linguistic variable in decision-making,” Int. J. Fuzz. Syst., 16(2), 196-203, 2014.

[14] Cables, E., Socorro Garcia-Cascales, M., "The LTOPSIS: An alternative to TOPSIS decision-making approach for linguistic variables,” Exp. Syst. Appl., 39, 2119-2126, 2012. Article (CrossRef Link)

[15] Liao, H.C., Xu, Z.S., "Approaches to manage hesitant fuzzy linguistic information based on the cosine distance and similarity measures for HFLTSs and their application in qualitative decision making,” Exp. Syst. Appl., 42, 5328-5336, 2015. Article (CrossRef Link)

[16] Liao, H.C.et al., "Hesitant fuzzy linguistic VIKOR method and its application qualitative multiple criteria decision making,” IEEE Trans. Fuzzy Syst., 23(5), 1343-1355, 2015. Article (CrossRef Link)

[17] Martinez, L., Herrera, F., “An overview on 2-tuple linguistic model for computing words in decision making: Extensions, applications and challenges,” Inform. Sci., 207(1), 1-18, 2012. Article (CrossRef Link)

[18] Pang, Q., Wang, H., Xu, Z.S., "Probabilistic linguistic term sets in multi-attribute group decision making,” Inform. Sci., 369, 128-143, 2016. Article (CrossRef Link)

[19] Pei, Z., Zou, L., Yi, L.Z., “A linguistic aggregation operator including weights for linguistic values and experts in group decision making,” Int. J. Uncertainty, Fuzziness and Knowl.-Based Syst., 21(6), 927-943, 2013. Article (CrossRef Link)

[20] Meng, D., Pei, Z., “On weighted unbalanced linguistic aggregation operators in group decision making,” Inform. Sci., 223, 31-41, 2013. Article (CrossRef Link)

[21] Z. Pei, D. Ruan, J. Liu, Y. Xu, “A linguistic aggregation operator with three kinds of weights for nuclear safeguards evaluation,” Knowl.-Based Syst., 28, 19-26, 2012. Article (CrossRef Link)

[22] Ren, F.L., Kong, M.M., Pei, Z., “A new hesitant fuzzy linguistic topsis method for group multi-criteria linguistic decision making,” Symmetry, 9, 289, 2017. Article (CrossRef Link)

[23] Liu, Z., Qin, K., Pei, Z., “A method for fuzzy soft sets in decision-making based on an ideal solution,” Symmetry, 9, 246, 2017.Article (CrossRef Link)

[24] Ou,Y., Yi, L., Zou, B., Pei, Z., "The linguistic intuitionistic fuzzy set TOPSIS method for linguistic multi-criteria decision makings,” Int. J. Comput. Intell. Syst., 11, 120-132, 2018. Article (CrossRef Link)

[25] Li, Z., Zhao, C., Pei, Z., “Operations on hesitant linguistic terms sets induced by archimedean triangular norms and conforms,” Int. J. Comput. Intell. Syst., 11, 514-524, 2018. Article (CrossRef Link)

[26] Torra, V., "Hesitant fuzzy sets,” Int. J. Intell. Syst., 25(6), 529-539, 2010. Article (CrossRef Link)

[27] Rodr'iguez, R.M., Mart'inez, L., Herrera, F., "Hesitant fuzzy linguistic term sets for decision making,” IEEE Trans. Fuzzy Syst., 20(1), 109-119, 2012. Article (CrossRef Link)

[28] Rodr'1guez R.M., Mart'ınez L., Herrera F., “A group decision making model dealing with comparative linguistic expressions based on hesitant fuzzy linguistic term sets," Inform. Sci., 241, 28-42, 2013. Article (CrossRef Link)

[29] Rodr' 1guez R.M., Mart'ınez L., Torra V., Xu Z.S., Herrera F., "Hesitant fuzzy sets: State of the art and future directions,” Int. J. Intell. Syst., 29(6), 495-524, 2014. Article (CrossRef Link) 
[30] Rodr'1guez R.M., Bedregal B, et al, “A position and perspective analysis of hesitant fuzzy sets on information fusion in decision making. Towards high quality progress,” Info. Fusion, 29, 89-97, 2016. Article (CrossRef Link)

[31] Wei C.P., Zhao N., Tang X.J., “Operators and comparisons of hesitant fuzzy linguistic term sets,” IEEE Trans. Fuzzy Syst., 22, 575-585, 2014. Article (CrossRef Link)

[32] Wang J.Q., Wu J.T., Wang J., Zhang H.Y., Chen X.H., "Interval-valued hesitant fuzzy linguistic sets and their applications in multi-criteria decision-making problems,” Inform. Sci., 288, 55-72, 2014. Article (CrossRef Link)

[33] Chen S.M., Hong J.A., "Multicriteria linguistic decision making based on hesitant fuzzy linguistic term sets and the aggregation of fuzzy sets,” Inform. Sci., 286, 63-74, 2014. Article (CrossRef Link)

[34] Wang J.Q., Wang J., Chen Q.H., Zhang H.Y., Chen X.H., “An outranking approach for multi-criteria decision-making with hesitant fuzzy linguistic term sets,” Inform. Sci., 280, 338-351, 2014. Article (CrossRef Link)

[35] Liao H.C., Xu Z.S., Zeng X.J., "Distance and similarity measures for hesitant fuzzy linguistic term sets and their application in multi-criteria decision making," Inform. Sci., 271, 125-142, 2014. Article (CrossRef Link)

[36] Liu H.B., Rodr'iguez R.M., “A fuzzy envelope for hesitant fuzzy linguistic term set and its application to multicriteria decision making,” Inform. Sci., 258, 220-238, 2014.

Article (CrossRef Link)

[37] Zhang Z., "Hesitant fuzzy power aggregation operators and their application to multiple attribute group decision making,” Inform. Sci., 234, 150-181, 2013.Article (CrossRef Link)

[38] Zhang Y.J., Wang Y.Z., Wang J.P., "Hesitant fuzzy linguistic multiple attribute decision making," in Proc. of 16th International Conference on Information Fusion; Istanbul, Turkey, pp. 1421-1426, 2013.

[39] Lee L.W., “Chen, S.M. Fuzzy decision making based on likelihood-based comparison relations of hesitant fuzzy linguistic term sets and hesitant fuzzy linguistic operators,” Inform. Sci., 294, 513-529, 2015. Article (CrossRef Link)

[40] Wu Z.B., Xu J.P., "Possibility distribution-based approach for MAGDM with hesitant fuzzy linguistic information,” IEEE Trans. Cyber., 46(3), 694-705, 2016. Article (CrossRef Link)

[41] Zeng S.Z., Merig'o J.M., Su W.H., "The uncertain probabilistic OWA distance operator and its application in group decision making,” Appl. Math. Model., 37, 6266-6275, 2013. Article (CrossRef Link)

[42] Merig'o J.M., Xu Y.J., Zeng S.Z., “Group decision making with distance measures and probabilistic information,” Knowl.-Based Syst., 40, 81-87, 2013. Article (CrossRef Link)

[43] Merig'o J.M., Casanovas M. et al, "Linguistic group decision making with induced aggregation operators and probabilistic information.,”Appl. Soft Comput., 24, 669-678,2014. Article (CrossRef Link)

[44] Merig'o J.M. et al, "Group decision making with expertons and uncertain generalized probabilistic weighted aggregation operators,” Eur. J. Oper. Res., 235, 215-224, 2014. Article (CrossRef Link)

[45] Merig'o J.M, "Probabilities in the OWA operator," Exp. Syst. Appl., 39, 11456- 11467, 2012. Article (CrossRef Link)

[46] Herrera F., Herrera-Viedma E., “Aggregation operators for linguistic weighted information,” IEEE Trans. Syst. Man Cybern. Part A: Syst. Humans, 27, 646-656, 1997. Article (CrossRef Link)

[47] Herrera F., Herrera-Viedma E., Verdegay J.L., "A sequential selection process in group decision making with a linguistic assessment approach,” Inform. Sci., 85, 223-239, 1995. Article (CrossRef Link)

[48] Xu Z.S., "Induced uncertain linguistic OWA operators applied to group decision making," Inf. Fusion, 7, 231-238, 2006. Article (CrossRef Link)

[49] Yager R.R., "On ordered weighted averaging aggregation operators in multicriteria decision making,” IEEE Trans. Syst. Man Cybern., 18(1), 183-190, 1988. Article (CrossRef Link)

[50] Merig'o J.M., Casanovas M., "Induced and uncertain heavy OWA operators,” Comput.Ind. Eng., 60, 106-116, 2011. Article (CrossRef Link) 
[51] Merig'o J.M., "A unified model between the weighted average and the induced OWA operator," Exp. Syst. Appl., 38, 11560-11572, 2011. Article (CrossRef Link)

[52] Yager R.R., “Constrained OWA aggregation,” Fuzzy Sets Syst., 81, 89-101, 1996.

Article (CrossRef Link)

[53] Arp R., Smith B. et al, "Building ontologies with basic formal ontology,” MitPress, 2015. Article (CrossRef Link)

[54] Calegari S., Ciucci D., "Fuzzy ontology, fuzzy description logics and fuzzy-owl," Lecture Notes in Computer Science, 4578, 118-126, 2007. Article (CrossRef Link) 


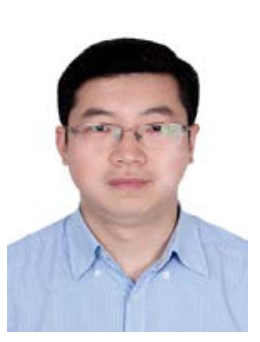

Mingming Kong is a lecturer at the School of Computer and Software Engineering in Xihua University, Chengdu, Sichuan, P.R. China. He received his M.S. degree in applied mathematics from Xihua University, Chengdu, Sichuan, P.R. China, in Dec. 2010. His current research interests include rough set theory, fuzzy set theory, linguistic information processing, and Spectrum Management.

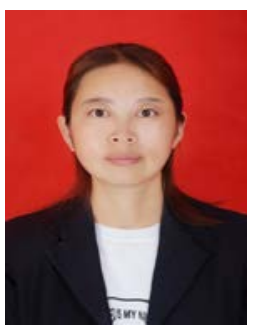

Fangling Ren received the M.S. degrees from Yan'an University, Yan'an, China, in 2010. She is currently a lecturer with the College of Mathematics and Computer Science, Yan'an University, Yan'an. Her research interests are probability and mathematical Statistics, financial mathematics and decision-making theory. She has nearly 20 research papers published in academic journals and has a co-author named Probability Statistics and Application.

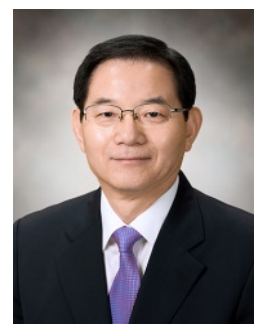

Doo-Soon Park received his $\mathrm{PhD}$ in Computer Science from Korea University in 1988. Currently, he is a professor in the Department of Computer Software Engineering at Soonchunhyang University, South Korea. He is Director of Wellness Service Coaching Center at Soonchunhyang University. He was President of KIPS(Korea Information Processing Society) in 2015, and Director of Central Library at Soonchunhyang University from 2014 to 2015. He was editor in chief of JIPS(Journal of Information Processing Systems) at KIPS from 2009 to 2012, and Dean of the Engineering College at Soonchunhyang University from 2002 to 2003 . He has served as an organizing committee member of international conferences including FutureTech 2016, MUE 2016, WORLDIT 2016, GLOBAL IT 2016, CUTE 2015, CSA 2015. His research interests include data mining, big data processing and parallel processing. He is a member of IEEE, ACM, KIPS, KMS, and KIISE.

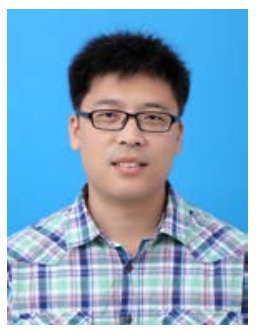

Fei Hao received the B.Sc. degree in Information and Computing Science and the M.Sc. degree in Computer Software and Theory from Xihua University, China, in 2005 and 2008, respectively, and the Ph.D. degree in Computer Science and Engineering from Soonchunhyang University, South Korea, in 2016. He is currently an associate professor with the School of Computer Science, Shaanxi Normal University, China. He has authored over 80 papers in international journals and conferences. He received five best paper awards from KISM 2012, GreenCom 2013, MUE 2015, UCAWSN 2015 and CUTE 2016. He is a recipient of the IEEE Outstanding Service Award at SmartData 2017, IEEE Outstanding Leadership Award at CPSCom 2013 and the 2015 Chinese Government Award for Outstanding Self-Financed Students Abroad. His research interests include social computing, ubiquitous computing, big data analysis and processing and mobile cloud computing.

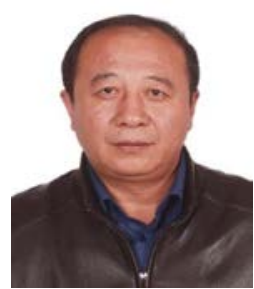

Zheng Pei received the M.S. and Ph.D. degrees from Southwest Jiaotong University, Chengdu, China, in 1999 and 2002, respectively. He is currently a Professor with the School of Computer and Software Engineering, Xihua University, Chengdu. His research interests are rough set theory, fuzzy set theory, logical reasoning, and linguistic information processing. He has nearly 70 research papers published in academic journals or conference. 